\title{
Piezoelectric Energy Harvesting: A Systematic Review of Reviews
}

\author{
Jafar Ghazanfarian ${ }^{1}$ (D), Mohammad Mostafa Mohammadi ${ }^{1, *}$ and Kenji Uchino ${ }^{2}$ (D) \\ 1 Mechanical Engineering Department, Faculty of Engineering, University of Zanjan, \\ Zanjan P.O. Box 45195-313, Iran; j.ghazanfarian@znu.ac.ir \\ 2 International Center for Actuators and Transducers, The Pennsylvania State University, \\ University Park, PA 16802, USA; kxu1@psu.edu \\ * Correspondence: dr.mohammadi@znu.ac.ir
}

Citation: Ghazanfarian, J.; Mohammadi, M.M.; Uchino, K. Piezoelectric Energy Harvesting: A Systematic Review of Reviews. Actuators 2021, 10, 312. https:// doi.org/ 10.3390/act10120312

Academic Editor: André Preumont

Received: 30 October 2021

Accepted: 23 November 2021

Published: 26 November 2021

Publisher's Note: MDPI stays neutral with regard to jurisdictional claims in published maps and institutional affiliations.

Copyright: (c) 2021 by the authors. Licensee MDPI, Basel, Switzerland. This article is an open access article distributed under the terms and conditions of the Creative Commons Attribution (CC BY) license (https:// creativecommons.org/licenses/by/ $4.0 /)$.

\begin{abstract}
In the last decade, an enormous amount of attention has been paid to piezoelectric harvesters due to their flexibility in design and the increasing need for small-scale energy generation. As a result, various energy review papers have been presented by many researchers to cover different aspects of piezoelectric-based energy harvesting, including piezo-materials, modeling approaches, and design points for various applications. Most of these papers have tried to shed light on recent progress in related interdisciplinary fields, and to pave the road for future prospects in the development of these technologies. However, there are some missing parts, overlaps, and even some contradictions in these review papers. In the present review of these review articles, recommendations for future research directions suggested by the review papers have been systematically summed up under one umbrella. In the final section, topics for missing review papers, concluding remarks on outlooks and possible research topics, as well as potentially misleading strategies, have been presented. The review papers have been evaluated based on their merits and subcategories and the authors' choice papers have been presented for each section based on clear classification criteria.
\end{abstract}

Keywords: energy harvesting; piezoelectric; energy conversion; renewable energies; micro-electromechanical systems

\section{Introduction}

Due to recent developments in portable and wearable electronics, wireless electronic systems, implantable medical devices, energy-autonomous systems, monitoring systems, and MEMS/NEMS-based devices, the procedure of small-scale energy generation may lead to a revolution in the development of compact power technologies.

Figure 1 presents the output power density variation versus the actual motor power for 2000 commercial electromagnetic motors. Electromagnetic motors are superior for the production of power levels higher than $100 \mathrm{~W}$. However, because the efficiency drops significantly below $100 \mathrm{~W}$, piezoelectric devices with a power density that is insensitive to their size will replace battery-operated small portable electronic equipment below the $50 \mathrm{~W}$ level. It is not logical to compare these energy harvesting systems at the MW power level. Hence, it is necessary for researchers to determine their original piezo-harvesting target, which should basically involve the replacement of compact batteries-one of the main forms of toxic waste-in sustainable society [1].

Dutoit et al. [2] provided a comparison based on the density of the output power, and indicated that the power densities of fixed-energy density sources extensively drop after just 1 year of operation. Thus, they require maintenance and repair if possible. Designing an effective power normalization scheme, as well as strain cancelation due to multiple input vibration components; optimizing the minimum vibration level required for positive energy harvesting; and prototype testing to eliminate the proof mass are among the suggestions for future works. 


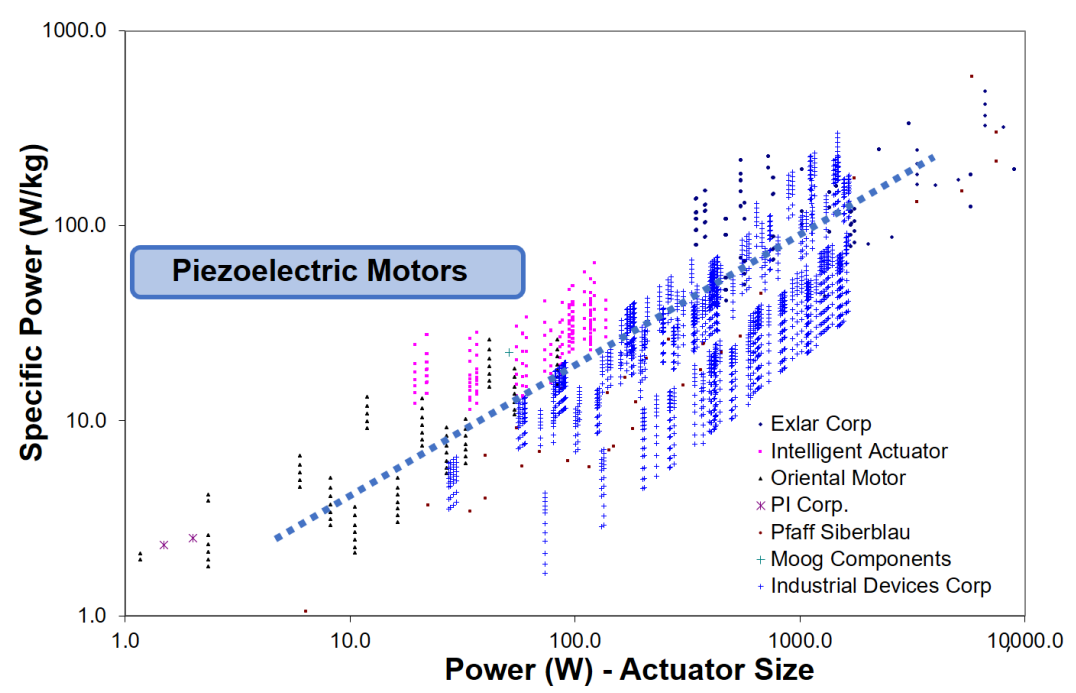

Figure 1. Comparison of the specific power with respect to the power [1].

The advantages of piezoelectric energy harnessing include the use of a simple structure without several additional components, the lack of a need for moving parts or mechanical constraints, environmental friendliness and ecological safety, portability, coupled operation with other renewable energies, the lack of a need for an external voltage source, compatibility with MEMS, easy fabrication with microelectronic devices, reasonable output power density, cost effectiveness, and scalability. Hence, piezo-materials are an excellent candidate to replace batteries, which have a short lifespan, for powering macro- to nanoscale electronic devices. Some disadvantages of piezo-harvesters are their high output impedance, producing relatively high output voltages at low electrical current, and rather large mechanical impedance.

The number of review papers on piezoelectric energy harvesting has extensively increased in the past decade. Due to the tremendous number of published review papers in this field, finding an appropriate review paper has become challenging. On the other hand, there are lots of overlaps, similarities, missing parts, and sometimes contradictions between different reviews. Therefore, the main motivation for the present paper was to present a systematic review of the review papers on piezoelectric energy harvesting. We tried to summarize all deficits, advantages, and missing parts of the existing review papers on piezo-energy harvesting systems.

An extensive search among database sources identified 91 review papers in diverse applications related to piezoelectric energy harvesting. As will be demonstrated later, such papers have presented different concluding remarks for the related areas of usage, materials, design approaches, and mathematical models. We tried to perform a very detailed search procedure with several keywords and search engines to cover all published review papers, as well as to find review papers without "piezo" directly mentioned in the title.

The statistics on publications during the last two decades, excluding conference papers, extracted using the keyword "piezo AND energy harvesting" from SCOPUS are shown in Figure 2. The results from SCOPUS included an overall total of 4435 documents, containing 874 open access papers, 130 book chapters, and 36 books. The national natural science foundation of China, the fundamental research funds for the central universities, and the national research foundation of Korea were the most frequent funding sponsors. The most common subject areas were engineering, material sciences, physics and astronomy, chemistry, and energy. An extrapolation, shown in the figure, anticipates the publication of about 2500 articles per year during the coming three years.

Due to the interdisciplinary nature of piezoelectric energy harvesting, predicting the behavior of piezo-generators is related to different thermo-electro-mechanical sciences, as well as material engineering. We have illustrated a systematic map of various aspects 
of piezo-energy harvesting in Figure 3. Different branches of connected sciences and applications include fabrication methods, hybrid systems, performance evaluation, size, utilization methods, configurations, modeling aspects, economic points, energy sources, optimization, the design of an electric interface, and the selection of proper materials. All sub-branches in the Figure will be discussed in subsections of the present paper.

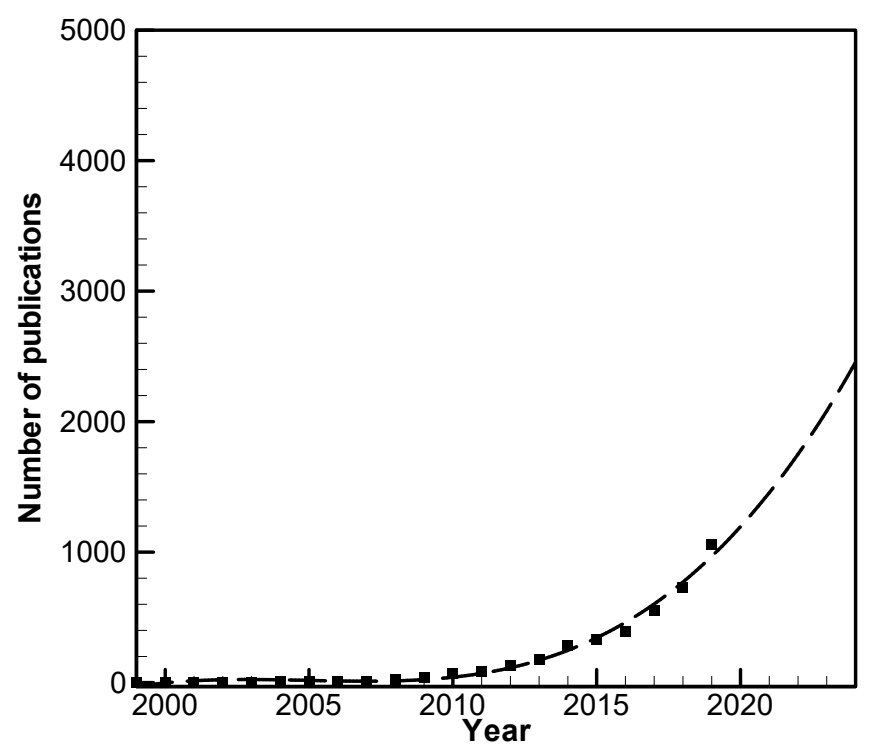

Figure 2. Statistics and future estimation of publications on piezoelectric energy harvesting.

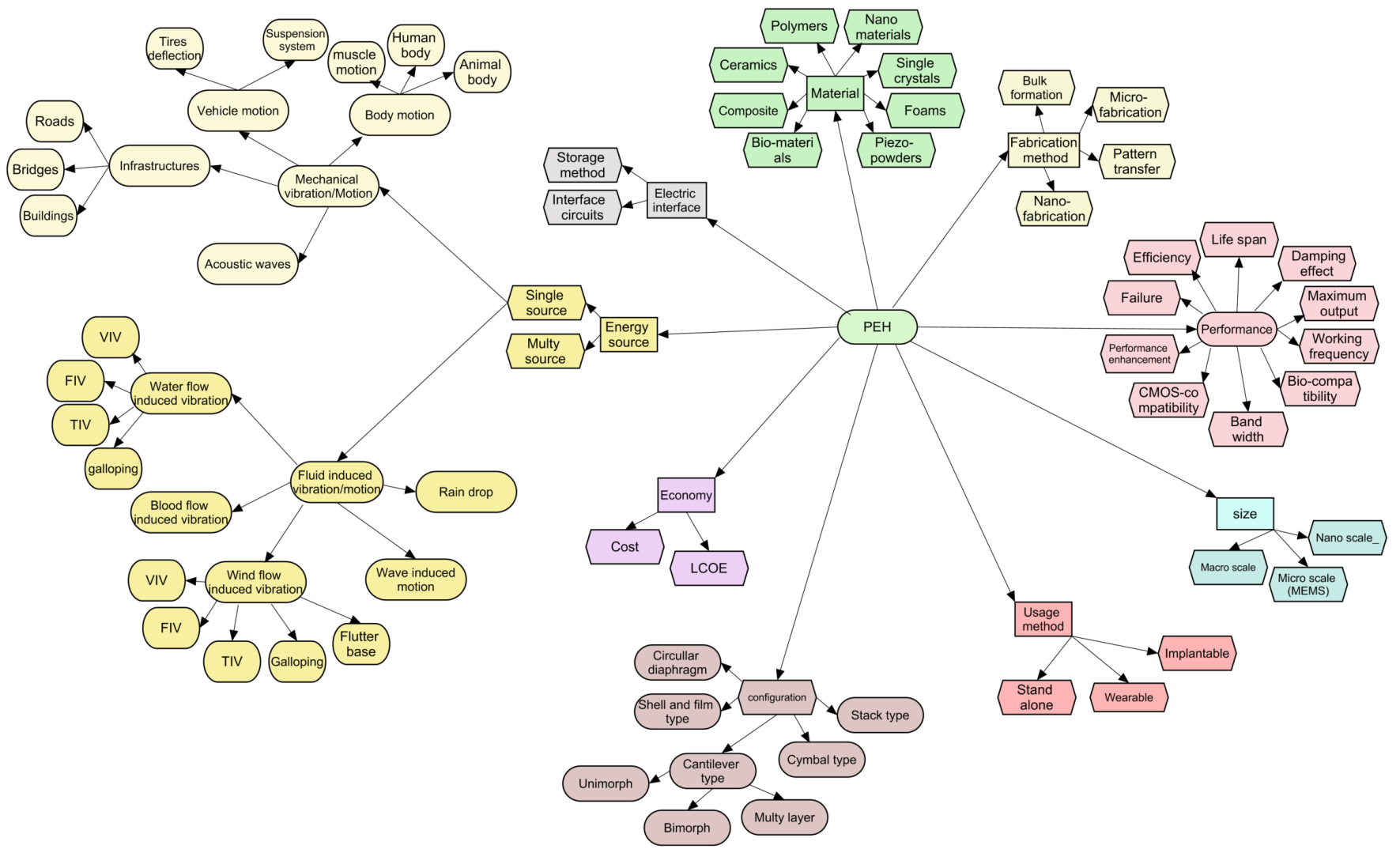

Figure 3. Strategic map of piezoelectric energy harvesting design aspects, modeling approaches, and applications. 
A review article is not an omnibus of the paper collection. A review should be written in order to criticize and/or praise each paper. The evaluation of the review papers and their contributions to the field will be presented based on the following criteria:

1. Having a solid evaluation philosophy used by the reviewer.

2. Presenting non-general future research directions in the summary/conclusion of the paper.

3. Paying attention to critical design aspects, such as the electromechanical coupling factor and actual resonance frequency.

4. Many papers report on the harvesting energy around the resonance range. Though the typical noise vibration is in a much lower frequency range, researchers measure the amplified resonance response (even at a frequency higher than $1 \mathrm{kHz}$ ).

5. If the harvested energy is lower than $1 \mathrm{~mW}$, which is lower than the required electric energy to operate a typical energy harvesting electric circuit with a DC/DC converter (typically around 2-3 $\mathrm{mW}$ ), it is somewhat difficult to describe the system as an energy harvesting device.

6. The complete energy flow or exact efficiency from the input mechanical noise energy to the final electrical energy in a rechargeable battery via the piezoelectric transducer is an important part of the review from the applicational/industrial viewpoint.

7. The number of sub-fields covered in the review paper.

8. The provision of a sufficient theoretical background on piezoelectric energy harvesting, practical material selection, device design optimization, and energy harvesting electric circuits, to help readers avoid "Google syndrome" [3].

9. The number of cited articles by each review paper has also been mentioned in a separate column in all tables. Since having a higher number of references is not a critical factor, we did not assign a score to this column. However, it may be helpful for readers to be aware of the number of reviewed papers in each article.

Our scoring strategy was as follows: 1 point for the number of conclusions reported, 1 point for the number of sub-categories covered, 2 points for paying attention to merits, and 1 point for reporting the minimum required energy output level. Details of scores for each part are presented in the tables inside brackets. Reviews with scores (rounded to two decimal places) less than 1.00, from 1.00 to less than 2.00, from 2.00 to less than 3.00, from 3.00 to less than 4.00 , and from 4.00 to 5.00 have been labeled with $\mathrm{E}$ to $\mathrm{A}$, respectively. It should be noted that the value of the minimum required output should be clearly addressed among the concluding remarks, conclusions, future directions, abstract, or introduction.

The outline of the paper is as follows. In the first section, the focus is on reviews about the design process, structure, material considerations, size effects, and mathematical modeling challenges. In the second part of the article, the main theme is evaluating applications of piezo-harvesters. The most common applications include vibrational energy sources, fluid-based harvesters, scavenging energy from ambient waste energies, and energy harnessing in biological applications. In the last section, a summary of future challenges, research directions, and missing review topics is presented.

\section{Reviews with Non-Focused Topics}

The papers discussed in this section are general review articles without a specific focal point. Safaei et al. [4] presented a review of energy harvesting using piezoelectric materials for the period from 2008 to 2018. This article is an update of their previous review [5], and covers lead-free piezo-materials, piezoelectric single crystals, high-temperature piezoelectricity, piezoelectric nanocomposites, piezoelectric foams, nonlinear and broadband transducers, and micro-electro-mechanical transducers. They also discussed several types of piezoelectric transducers, the mathematical modeling, energy conditioning circuitry, and applications such as fluid flow energy harvesters, windmill-style harvesters, flutterstyle harvesters, / wearable devices, implantable devices, animal-based systems, infrastructure, vehicles, and multifunctional/multi-source energy harvesting systems. Several 
useful illustrations have been presented in the paper, which sum up different technologies in a unified framework. However, their brief recommendations for future horizons in the field, including the fabrication of piezoelectric nanofibers, piezoelectric thin films, printable piezoelectric materials, exploiting the internal resonance of structures, and the development of metamaterials and metastructures, may be extended to cover other aspects presented in Table 1.

Taware and Deshmukh [6] briefly reviewed a number of studies in the field of piezoelectric energy harvesting. They mentioned the advantages and disadvantages of some piezoelectric materials. They examined cantilever-based piezoelectric energy harvesters, their related design points, and mathematical modeling. Anton and Sodano [5] reviewed some general topics published between 2003 to 2006, discussing efficiency improvement, configurations, circuitry and methods of power storage, implantable and wearable power supplies, harvesting from ambient fluid flows, micro-electro-mechanical systems, and selfpowered sensors without a clear classification. They reported that future directions included the development of a complete self-powered device that includes a combination of a power harvester, storage, and application circuitry. Furthermore, they declared that the enhancement of energy generation and storage methods, along with decreasing the power requirements of electronic devices, may be a prime target for future studies. Sharma and Baredar [7] analyzed the current methods used to harvest energy from vibrations using a piezoelectric setup in the low-range frequency zone by analyzing piezoelectric material properties based on modeling and experimental investigations. They indicate that the disadvantages of piezo-harvesters are depolarization, sudden breaking of the piezo layer due to high brittleness and a poor coupling coefficient, the poor adhesive properties of PVDF material, and the relatively low electromagnetic coupling coefficient of PZT. They reported that the design of high-efficiency energy harvesters, the invention of new energy harvesting designs by exploring non-linear benefits, and the design of portable compact-size systems with integrated functions are forthcoming challenges.

Mateu and Moll [8] presented an overview of several methods to design an energy harvesting device for microelectronics, depending on the type of available energy. They summarized the power consumption of microelectronic devices and explained the working principals of piezoelectric, electrostatic, magnetic induction, and electromagnetic radiationbased generators. Calio et al. [9] reviewed the material properties of about 19 piezomaterials, the piezo-harvesters' operating modes, resonant/non-resonant operations, the optimal shape of the beam, the frequency tuning, the rotational device configurations, the power density and bandwidth, and the conditioning circuitry. They tried to present a selection guide between piezoelectric materials based on the power output and the operating modes. They concluded that the resonant $d_{33}$ cantilever beam needs to be optimized and the $d_{15}$ harvester is still too complex to be fabricated but has great potential. This paper may be a good suggestion for beginners to start their research in the field of piezoelectric energy harvesting. Sun et al. [10] conducted a review of the applications of piezoelectric harvesters. However, they expressed everything in a nutshell. Such topics require closer considerations. Khaligh et al. [11] addressed piezoelectric and electromagnetic generators suitable for human-powered and vibration-based devices, including resonant, rotational, and hybrid devices. Brief information was been presented about hybrid generators using an imbalanced rotor, which requires more in-depth investigations in future reviews. Batra et al. [12] reviewed mathematical modeling and constitutive equations for piezomaterials, lumped parameter modeling, the mechanisms of piezoelectric energy conversion, and the operating principles of piezoelectric energy harvesters. There was also a very short review paper [13] that focused mainly on some points about the history of the piezoelectric effect, piezo-materials, and applications such as harvesting from footsteps and roads.

Although most of the aforementioned general review papers have more or less similar titles, they differ in terms of their scientific depth and the number of reviewed items. Some papers, such as [9], have focused on design strategies for piezoelectric energy harvesters. They have attempted to present a guide for the selection of piezoelectric materials as 
harvesters. Moreover, almost all the mentioned reviews suffer from weak classifications, stemming from the generality of their topics. 
Table 1. Overall evaluation of review papers written about non-focused topics on piezoelectric energy harvesting. "Cons." stands for conclusions. Numbers in brackets are scores for each item. Conclusions: 1: efficiency/performance improvement, 2: frequency tuning, 3: safety issues, 4: costs, hybrid harvesters, 5: non-linear models, 6: battery replacement, 7: miniaturization, 8: steady operation, 9: more efficient materials. Merits: 1: electromechanical coupling factor, 2: realistic resonance, 3: energy flow, 4: paying attention to the range of output power. Sub-categories: 1: microscale, 2: electrostatic, 3: magnetic induction, 4: electromagnetic radiation, 5: thermal energy, 6: circuit, 7: wearable device, 8: ambient fluid flow, 9: sensors, 10: material, 11: human-related, 12: vibration, 13: hybrid device, 14: modelling, 15: road and shoe, 16: fluids, 17: animal-related.

\begin{tabular}{lccccccc}
\hline \# Cons. & Minimum Required Output & \# Refs. & Merits & Sub-Categories & Ref. & Grade & Highlights \\
\hline $6(0.67)$ & microW to milliW $(0)$ & 474 & $1,2,3,4(2.00)$ & $1,6,10,11,14,15,16,17(0.47)$ & Safaei et al. [4] & B & High-temperature devices, metamaterials \\
\hline $5(0.56)$ & 375 microW $(1)$ & 14 & $2,4(1.0)$ & $11,12,14(0.18)$ & Taware and Deshmukh [6] & C & \\
\hline $5(0.56)$ & microW $(0)$ & 90 & $1,3,4(1.5)$ & $1,6,7,8,9,10(0.35)$ & Anton and Sodani [5] & C & \\
\hline $6(0.67)$ & $-(0)$ & 70 & $1,2,4(1.5)$ & $10,14(0.12)$ & Sharma and Baredar [7] & C & Depolarization, sudden breaking of piezo layer due to high brittleness \\
\hline $4(0.44)$ & 100 microW $(1)$ & 33 & $4(0.50)$ & $1,2,3,4,5,6(0.35)$ & Mateu and Moll [8] & C & A discussion on power consumption of microelectronic devices \\
\hline $4(0.44)$ & $-(0)$ & 153 & $1,2,4(1.5)$ & $6,10,11,14(0.24)$ & Calio et al. [9] & C & Optimal shapes, buckling \\
\hline $3(0.33)$ & 1.3 milliW(1) & 16 & $4(0.50)$ & $-(0)$ & Sun et al. [10] & D & Comparison with energy from wind, solar, geothermal, coal, oil, and gas \\
\hline $3(0.33)$ & microW to milliW $(0)$ & 54 & $1,4(1.0)$ & $2,11,12,13(0.24)$ & Khaligh et al. [11] & D & \\
\hline $1(0.11)$ & microW to milliW $(0)$ & 95 & $4(0.5)$ & $10,11,12,14,15(0.29)$ & Batra et al. [12] & E & \\
\hline $1(0.11)$ & $-(0)$ & 13 & $-(0)$ & $10,14,15(0.18)$ & Sharma et al. [13] & E & - \\
\hline
\end{tabular}

The results of the evaluation of generally-written review papers on piezoelectric energy harvesting have been presented in Table 1 . The table contains different sub-categories, the range of output power, the number of reviewed articles, the merits, general conclusions, and some other information. The grade for each paper was computed based on the number of merits, the number of subcategories, the number of concluding remarks, and declaration of the minimum required output power.

\section{Design and Fabrication}

The design of piezoelectric energy harvesters is one of the most critical steps in attaining high-performance energy harvesting. We divided this section to three subsections, including the materials, structures, and electric interface circuits of PEHs.

\subsection{Materials}

The choice of a suitable piezoelectric material is a critical step in designing energy harvesters [14]. Thus, many of the review papers in the field of energy harvesters have addressed the topic of piezoelectric materials. Different performance metrics have been selected for comparing piezoelectric materials in diverse applications. In actuating and sensing applications, the piezoelectric strain and piezoelectric voltage constants are appropriate criteria. However, the electromechanical coupling factor, power density, mechanical stiffness, mechanical strength, manufacturability, and quality factor are the most important factors for energy harvesting. Furthermore, the operating temperature is important in material selection [15].

Li et al. [16] divided piezoelectric materials into four categories (ceramics, single crystals, polymers, and composites) based on their structural characteristics. They described the general properties of these four piezo-material categories, and compared some of the most important candidate materials from these categories in terms of the piezoelectric strain constant, piezoelectric voltage constant g, electromechanical coupling factor $\mathrm{k}$, mechanical quality factor $Q$, and the dielectric constant e. They commented that piezoelectric ceramics and single crystals have much better piezoelectric properties than piezoelectric polymers, which is due to strong polarizations in their crystalline structures. On the other hand, piezoelectric ceramics and single crystals are more rigid and brittle then piezoelectric polymers. Both piezoelectric properties and mechanical properties are important in the selection of a certain piezoelectric material for a specific piezoelectric harvesting application. Other important parameters in selecting suitable materials are the application frequency, the available volume, and the form in which mechanical energy is fed into the system. In order to harvest the maximum amount of energy, the piezoelectric energy harvester 
should operate at its resonance frequency. However, in many cases, such as low-frequency applications, it is impractical to match the resonance frequency of the piezoelectric with the input frequency of the host structure. They demonstrated that for low-frequency applications in off-resonance conditions the piezoelectric element can be approximated as a parallel plate capacitor and for harvesting more electric energy the product of the piezoelectric strain constant and the piezoelectric voltage constant should be high. On the other hand, for near-resonance conditions, the optimum output power of the harvester is independent of piezoelectric properties of the piezo-element but the maximum output voltage depends on the piezoelectric strain constant. It is obvious that the selection of a suitable piezomaterial for a piezo-harvester depends on working conditions, and it makes the selection of piezo-material more complex. The energy density of piezoelectric materials was not reported. The focus was on macroscale piezomaterials and micro- and nono-scale materials were not covered.

Narita and Fox [17] reviewed three categories including piezoelectric ceramics/ polymers, magnetostrictive alloys, and magnetoelectric multiferroic composites. Their review included a description of the properties of PZT, PVDF, and ZnO. They compared some of the piezoelectric materials based on their piezoelectric coefficients (Figure 4). They also remarked on some advantages and disadvantages of traditional piezoelectric ceramics, piezoelectric polymers, and composites. They focused on the characterization, fabrication, modeling, simulation, durability and reliability of piezo-devices. Based on their analysis, future directions include device size reduction, to make devices suitable for nanotechnology, as well as the optimization, and development of accurate multi-scale computational methods to link atomic, domain, grain, and macroscale behaviors. The investigation of temperature-dependent properties, the development of materials and structures capable of withstanding prolonged cyclic loading, studies of the duration of electro-magneto-mechanical properties, and fracture/fatigue studies are other recommendations for future research. The review did not report on some important mechanical and piezoelectric properties of the piezo-materials, such as the electromechanical coupling factor, the quality factor, and the mechanical strength and mechanical stiffness, and the materials were compared based on their piezoelectric coefficients and the output power of the energy harvesters.

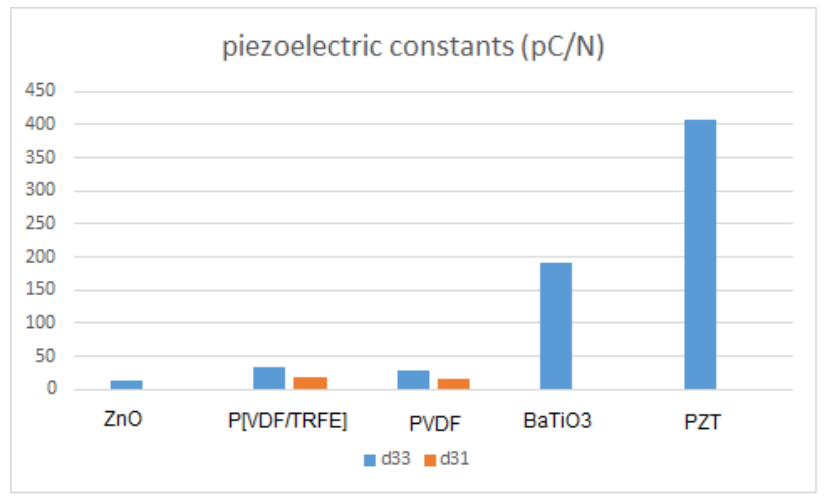

Figure 4. Piezoelectric coefficient range for some piezoelectric materials [17].

Safaei et al. [4] reviewed the recent progress in the field of piezoelectric ceramics, such as soft and hard PZTs, piezoelectric polymers including PVDF, piezoelectric single crystals, lead-free piezoelectrics, high temperature piezoelectrics, piezoelectric nanocomposites, and piezoelectric foams. They reported on the piezoelectric coefficient and the maximum output voltage for some of these materials without describing the geometry of the piezoelectric harvester. The brittleness of PZTs and the existence of health risks in PZT ceramics due to the toxicity of lead are the most important challenges of using PZTs, which motivates the development of lead-free flexible and high-performance piezoelectric materials. They concluded that the need for the enhancement of electromechanical, thermal, 
and biocompatible properties has led to the introduction of new piezoelectric materials, including new lead-free piezoelectrics, high-temperature piezoelectrics, piezoelectric foams, and piezoelectric nanocomposites. The paper explained many piezo-materials; however, it did not offer a systematic comparison between the piezoelectric materials in terms of their piezoelectric and mechanical properties. It seems that its main target was only to report the recent progresses in the field. Furthermore, the minimum required output power for the piezoelectric harvesters was not remarked upon.

Zaarour et al. [18] summarized the energy harvesting technologies developed based on piezoelectric polymeric fibers, inorganic piezoelectric fibers, and inorganic nanowire. The paper contains a review of piezoelectric fibers and nanowires with respect to the peak voltage, the peak current, the active area, and their advantages, without describing the working conditions and mechanical structure of the related piezoelectric energy harvester. Perhaps due to the lack of available data on properties of nano-scale piezoelectric materials, the paper does not present a comparison between the selected materials in terms of their piezoelectric and mechanical properties. The reported output powers are in the range of microwatts, which is not enough for the powering of real electronic systems and circuits. They concluded that standardizing the performance of the piezo-nanogenerator, developing effective packaging technology, the packaging of nano-piezo-harvesters, commercializing products for harsh environments, finding a suitable approach to enhance the electrical outputs, and augmenting the durability and the output stability are some future horizons.

Yuan et al. [19] introduced dielectric electroactive polymers as promising replacements for conventional piezoelectric materials. Electroactive polymers are lightweight, flexible, ductile, and manufactured at low cost, with high strength-to-weight ratio, low mechanical impedance, and the ability to endure large strains. Dielectric polymers require high voltage to realize energy cycles, which may lead to the breakdown of the device. Piezoelectric materials are employed in energy harvesters because of their compact configuration and compatibility. However, these materials have inherent limitations, including aging, depolarization, and brittleness. In comparison, electrostrictive polymers are promising candidates to replace piezoelectric materials in vibration energy harvesting cases. The challenge in the design of electroactive polymer energy harvesters is to develop systems that are capable of ensuring a constant initial voltage on the polymer at a small cost.

There are some other review papers which have focused on several issues in the field of piezoelectric materials. Piezoelectric polymers were reviewed in papers such as a review by Mishara et al. [20]. High-temperature single crystals are the subject of Priya's paper, which presented a comparative study of the main high-temperature piezoelectric single crystals. Bio-piezoelectric materials were described by Liu et al. [21]. They have also reviewed micro- and nano-fabrication techniques for micro-/nanoscale energy harvesters. Useful information on micro-/nanoscale piezoelectric materials may be found in the work of Gosavi et al. [14]. They defined a systematic roadmap to select piezoelectric materials for micro and nanoscale energy harvesters. They pointed out that $\mathrm{ZnO}$ thin film is the most widely-used structure in micro- and nanoscale harvesters, and can be economically synthesized in arbitrary sizes and shapes. A detailed comparison between traditional macro materials and new micro/nano piezoelectric materials in terms of dielectric, mechanical and piezoelectric properties was performed by Bowen et al. [22]. They mentioned some points about high-temperature harvesting, related to the Curie temperature, light harvesting into chemical or electrical energy, and optimization algorithms. Their investigation contains parameters such as the pyroelectric coefficient (harvesting from temperature fluctuations), the electro-mechanical coupling factor, the mechanical quality factor, the constant-strain relative permittivity, the constant-stress relative permittivity, the piezoelectric coefficient, and the elastic constant of piezoelectric materials. For high-strain applications, they suggested polymeric or composite-based systems. Their suggested future directions are the understandingand development of new materials and the gaining of a strong scientific underpinning for the technology, as well as reliable measurements. 
Most review papers have tried to compare piezoelectric materials and draw a roadmap for the selection of an appropriate material for energy harvesters. However, the choice of material is strictly dependent on type of the energy harvester; its working conditions; and the cost, accessibility, and ease of fabrication/synthesis of the piezoelectric material. For example, Ullah Khan and Ahmad [23], who have reviewed vibrational energy harvesters utilizing bridge oscillations, pointed out that the main selection criteria for piezoelectric vibrational energy harvesting are the dielectric constant, the Curie temperature, and the modulus of elasticity of the material.

Piezoelectric materials with a high elastic modulus can be an appropriate choice for high acceleration vibrations. However, piezoelectric materials such as lead lanthanum zirconate titanate, which has a high dielectric constant, perform very well in low-acceleration vibrational environments. Furthermore, due to the ease of the in situ fabrication of lead zirconate titanate (PZT) with the sol-gel technique, and its easy integration with other microfabrication processes, PZT has been largely utilized in most of these applications.

As another example, we can point out the selection of a desirable piezoelectric material for walking-energy-harvesting applications. Based on a review performed by Maghsoudi Nia et al. [24], this application required an incombustible, chemically resistant, low-price material, which should be unbreakable under harsh conditions. The mentioned criteria have made PVDF more suitable than PZT for the most piezoelectric devices harnessing energy from walking. Most of the review papers have contented themselves with reporting some of the electromechanical properties of piezoelectric materials, and providing scant information on the accessibility, relative cost, chemical properties, ease of fabrication, and suitable working conditions of different piezoelectrics. The lack of such information indicates the need for further research and also the necessity of more comprehensive and application-based reviews on piezoelectric materials.

The results of the evaluation of review papers on piezoelectric materials have been presented in Table 2. The table also contains different sub-categories, the range of output power, the number of reviewed articles, the merits, general conclusions, and some other descriptions. The rank of each paper was computed based on the number of merits, the number of subcategories, the number of concluding remarks, and a clear emphasis on the value of the minimum required output power.

As indicated in Table 1, with the exception of a few papers such as [16], other reviews suffer from a lack of reported data on mechanical piezoelectric materials, their fabrication methods, and other figures of merit in the selection of materials. Furthermore, with the exception of a few papers, such as [17], which has pointed out the energy required for powering the electronic devices, other papers have neglected to report the minimum required energy for an energy harvester. 


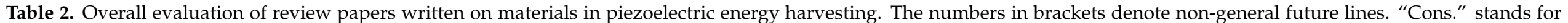

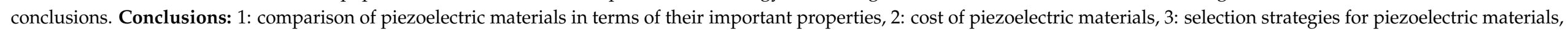

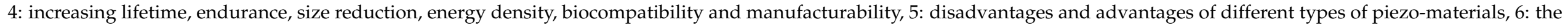

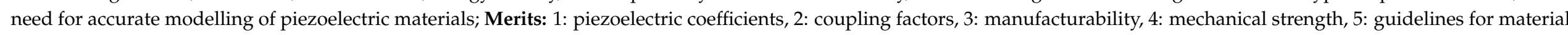

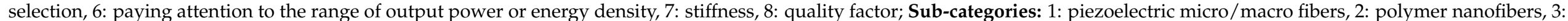

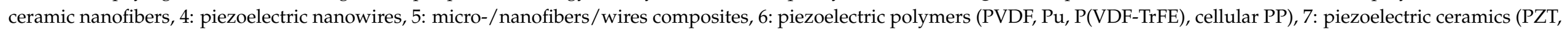

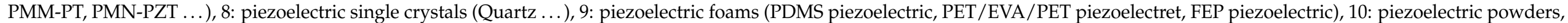

11: piezoelectric composites (PVDF with nanofillers, non-piezoelectric polymer with BaTiO3), 12: bio materials.

\begin{tabular}{|c|c|c|c|c|c|c|c|}
\hline \# Cons. & $\begin{array}{l}\text { Minimum Re- } \\
\text { quired Output }\end{array}$ & \# Refs. & Merits & $\begin{array}{l}\text { Sub- } \\
\text { Categories }\end{array}$ & Ref. & Grade & Highlights \\
\hline $4(0.67)$ & $\begin{array}{l}\text { microW to } \mathrm{mW} \\
\text { (1) }\end{array}$ & 120 & $\begin{array}{l}1,2,3,5,6,8 \\
(1.50)\end{array}$ & $\begin{array}{l}6,7,8,11 \\
(0.33)\end{array}$ & Li et al. [16] & B & $\begin{array}{l}\text { 1. the current state of research on piezoelectric energy harvesting devices for low-frequency }(0-100 \mathrm{~Hz}) \text { appli- } \\
\text { cations and the methods that have been developed to improve the power outputs of the piezoelectric energy } \\
\text { harvesters are reviewed. } 2 \text {. The selection of the appropriate piezoelectric material for a specific application and } \\
\text { methods to optimize the design of the piezoelectric energy harvester are discussed. }\end{array}$ \\
\hline $4(0.67)$ & $\begin{array}{l}\text { microW to } \mathrm{mW} \\
\text { (1) }\end{array}$ & 175 & $1,3,4,6(1)$ & $\begin{array}{l}1,6,7,8,11 \\
(0.42)\end{array}$ & Narita and Fox [17] & B & $\begin{array}{l}\text { 1. The harvested power of PZT-based PEHs with different structures are reported. } 2 \text {. The recent advances in the } \\
\text { field of PEHs made of PVDF, and polymer based composite piezoelectrics are reported, comparing the output } \\
\text { power of some piezoelectric energy harvesters. }\end{array}$ \\
\hline $3(0.50)$ & microW (1) & 24 & $2,6,9(0.75)$ & $6,8(0.17)$ & Lefeuvre [25] & C & $\begin{array}{l}\text { 1. Figures of merit for energy conversion efficiency. 2. Figure of merit for piezoelectric materials. 3. Comparison } \\
\text { of one-, two-, and three-stage electric power interfaces }\end{array}$ \\
\hline $3(0.50)$ & $\begin{array}{l}\text { microW to } \mathrm{nW} \\
(0)\end{array}$ & 474 & $\begin{array}{l}1,3, \quad 6,7 \\
(1.00)\end{array}$ & $\begin{array}{l}1,2,3,4,5,7 \\
8,9,11(0.75) \\
\end{array}$ & Safaei et al. [4] & $\mathrm{C}$ & $\begin{array}{l}\text { Recent advances in the field of piezoelectric materials are reported. Review of some novel piezoelectric materials } \\
\text { such as piezoelectric foam and high-temperature materials }\end{array}$ \\
\hline $4(0.67)$ & microW (0) & 446 & $1,3,5,6(1)$ & $\begin{array}{l}2,3,6,7,8,9 \\
(0.50)\end{array}$ & Liu et al. [21] & $\mathrm{C}$ & $\begin{array}{l}\text { 1. Report on recent progress in the field of piezoelectric materials. 2. Description of fabrication techniques for } \\
\text { many piezoelectric materials in energy harvesting applications. 3. Explanation of the main frequency bandwidth } \\
\text { broadening techniques. } 4 \text {. Classification of piezoelectric materials, fabrication techniques, and frequency } \\
\text { bandwidth broadening techniques. }\end{array}$ \\
\hline $4(0.67)$ & microW (0) & 173 & $3,4,5,6(1)$ & $\begin{array}{l}1-2-3-4-5 \\
(0.42)\end{array}$ & Zaarour et al. [18] & $\mathrm{C}$ & $\begin{array}{l}\text { 1. Manufacturing methods for nanofibers and wires. } 2 \text {. Contains mention of output voltages and currents of } \\
\text { nano-/micro-materials. 3. Comparison of nano-/micro-materials based on maximum voltage and currant and } \\
\text { active area. }\end{array}$ \\
\hline $2(0.33)$ & $\mathrm{mW}(0)$ & 50 & $\begin{array}{l}1,4,6,7,8 \\
(1.25)\end{array}$ & $6,7(0.17)$ & Yoan et al. [19] & $\mathrm{D}$ & $\begin{array}{l}\text { 1. Introduction of electrostrictive and dielectric electro-active polymers. 2. Performance comparison of PZT, } \\
\text { PVDF, and DEAPs and electrostrictive polymers. Description of the industrial challenges for dielectric electro- } \\
\text { active polymers. }\end{array}$ \\
\hline $3(0.50)$ & microW(0) & 158 & $1,2,3(0.75)$ & $\begin{array}{l}6,7,8,11 \\
(0.33)\end{array}$ & Mishra et al. [20] & $\mathrm{D}$ & $\begin{array}{l}\text { The article basically aims at exploring the basic theory behind the piezoelectric behavior of polymeric and } \\
\text { composite systems and comparing the important types of piezoelectric polymers and composites. The article } \\
\text { describes the piezoelectric properties of many piezo-polymers and polymer composites. }\end{array}$ \\
\hline $3(0.50)$ & microW (0) & 216 & $1,2,9(0.75)$ & $6,7,8(0.25)$ & Bowen et al. [22] & $\mathrm{D}$ & $\begin{array}{l}\text { Reviews some resent topics such as piezoelectric light harvesting, pyroelectric based harvesting, and nanoscale } \\
\text { pyroelectric systems }\end{array}$ \\
\hline $2(0.33)$ & $\begin{array}{l}\text { microW to } \mathrm{mW} \\
(0)\end{array}$ & 16 & $1,2,5,8(1)$ & $7(0.08)$ & $\begin{array}{l}\text { Mukherjee and } \\
\text { Datta [26] }\end{array}$ & $\mathrm{D}$ & 1. Effect of load resistance on the output power of PEHs. 2. Selection criteria for piezoelectric ceramics \\
\hline
\end{tabular}




\subsection{Structure}

All piezoelectric energy harvesters include a mechanical part (or transduction part) to convert the input mechanical energy into the electric charges in the piezoelectric element, and an electric part that maintains the electric charges and converts them into a suitable form of electric output, such as direct voltage. The design of the mechanical part of a piezoelectric energy harvester usually includes the determination of its size, configuration, working modes, and the selection of appropriate materials to enhance its performance characteristics, such as the output electric energy, the conversion efficiency and the working bandwidth. The size of the piezoelectric energy harvester may vary from the micro- and nanoscale (lower than $0.01 \mathrm{~cm}^{3}$ ) to the macroscale $\left(75 \mathrm{~cm}^{3}\right.$ ) [2].

Based on the literature, piezoelectric energy harvesters can be classified according to various viewpoints. From the viewpoint of operating frequency, they may be categorized into two main sections: resonant-type devices that operate at or near their resonance frequency, and non-resonant systems that do not depend on any specific frequency. Piezoelectric energy harvesters may harvest energy from motions in a unique direction or from multiple directions. Accordingly, they may be single-directional or multi-directional harvesters. Furthermore, they can have a single or several vibration modes (multi-modal harvesters). From the viewpoint of governing dynamic models, piezoelectric harvesters may be linear or non-linear [27]. As indicated in Figure 3, their configuration can be classified as cantilever-type, stack-type, cymbal-type, circular-diaphragm-type, or the shelland film-types.

Uchino [28] started his review by mentioning the historical background of piezoelectric energy harvesting, and explaining several important misconceptions. He reviewed the different design approaches followed by mechanical, electrical, and MEMS engineers. He remarked that there are three major phases associated with piezoelectric energy harvesting: (i) mechanical-mechanical energy transfer, (ii) mechanical-electrical energy transduction, and (iii) electrical-electrical energy transfer, to accumulate the energy into a rechargeable battery. Figure 5 represents these three major phases. In order to provide comprehensive strategies on how to improve the efficiency of the harvesting system, step-by-step detailed energy flow analysis is essential. It was mentioned that the five important figures of merit in piezoelectrics are the piezoelectric strain constant $d$, the piezoelectric voltage constant $g$, the electromechanical coupling factor $k$, the mechanical quality factor $Q_{m}$, and the acoustic impedance $Z$. Furthermore, the energy transfer rates for piezoelectric energy harvesting systems with typical stiff cymbals and flexible piezoelectric transducers were evaluated for the three aforementioned phases/steps. Moreover, a hybrid energy harvesting device that operates under either magnetic and/or mechanical noises was introduced. It was concluded that remote signal transmission, energy accumulation in rechargeable batteries, discovering an ingenious idea for combining nano-devices in parallel, and enhancing energy density in medical applications represent important future research fields. It was declared that a clear future perspective for NEMS and MEMS piezoelectric harvesters is missing due to their low energy levels (on the order of $\mathrm{pW}$ to $\mathrm{nW}$ ). We need to develop ingenious ideas concerning how to combine thousands of nanodevices in parallel and synchronously in phase. A description of the performance improvement techniques for non-resonant and resonant energy harvesters is missing in this article.

Priya [29] classified the energy harvesting approaches into two categories: (1) power harvesting for sensor networks using the MEMS/thin/thick-film approach, and (2) power harvesting for electronic devices using the bulk approach. His review article covered the latter category in more detail. He listed almost all the energy sources available in one's surroundings which may be used for energy harvesting and commented that the selection of the energy harvester-as compared to other alternatives, such as batteries-depends on two main factors: cost effectiveness and reliability. Furthermore, he reported on the daily average power consumption for a wearable device, and of common household devices. Next, comparisons of the energy density for the three types of mechanical-to-electrical 
energy converters, including electrostatic, electromagnetic, and piezoelectric devices, were performed. The results are represented in Figure 6. He concluded that piezoelectric converters are a prominent choice for mechanical-to-electric energy conversion because the energy density is three times higher as compared to electrostatic and electromagnetic devices. He provided a review of piezo-harvesters appropriate for light-weight flexible systems with easy mounting, a large response, and low-frequency operation, called the low-profile piezotransducer in on/off-resonance conditions. A good discussion of piezoelectric polymers, energy storage circuits, and microscale piezo-harvesting devices is available in the article. Priya mentioned that the electrical power generated by a piezoelectric energy harvester is inversely proportional to the damping ratio, which should be minimized through proper selection of the material and design. He also summarized the conditions leading to the appearance of maximum efficiency in low-profile piezoelectric energy harvesters. An interesting part of this paper is the description of the piezoelectric material selection procedure for on/off-resonance conditions. However, a description of performance improvement techniques for enhancing the system frequency response is missing from this article.

$\begin{array}{lll}\text { phase } 1 & \text { phase 2 } & \text { phase 3 } \\ \text { Mechanical } & \text { Mechanical - elecrical } & \text { Electrical energy } \\ \text { energy transfer } & \text { energy transduction } & \text { transfer }\end{array}$

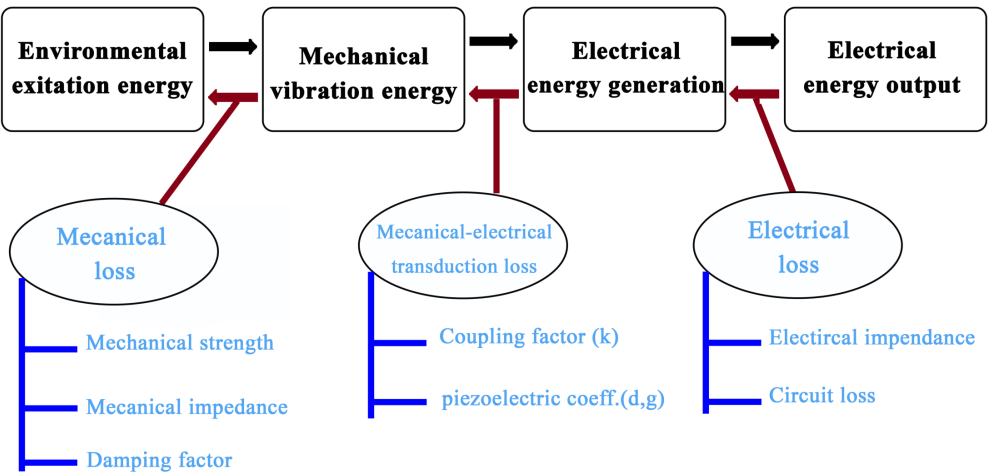

Figure 5. Three major phases associated with piezoelectric energy harvesting [28].

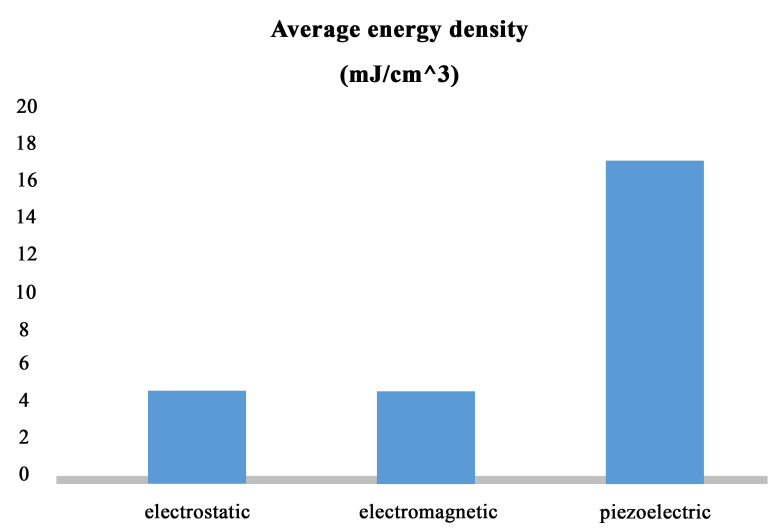

Figure 6. Comparison of the energy density for the three types of mechanical-to-electrical energy converters [29].

Yang et al. [30] commented that from the perspective of applications, the output power of the harvester and its operational frequency bandwidth are the two metrics that are the most useful for product development engineers. They explained the material selection procedure for piezoelectric energy harvesters in off-resonant conditions and remarked as to why PZTs are still the most popular piezoelectric materials for energy harvesters. They stated that linear resonant harvesters are not suitable for the harvesting of energy from broadband or frequency-varying excitations, and in these conditions nonlinear energy harvesters have been proven to be able to exhibit a broadband performance. Therefore, 
researchers have explored monostable, bistable, and tristable systems and developed some frequency tuning approaches, such as multi-cantilever structures, bistable composite plate designs, and passive and active stiffness-tuning technologies. They commented, in regard to nonlinear energy harvesters, that keeping nonlinear harvesters in high-energy oscillation states, especially under weak excitations, is a difficult task. Especially in cases with zero initial conditions, nonlinear harvesters usually follow low-energy orbits, which results in small-amplitude voltage responses. Thus, maintaining the nonlinear PHE in high-energy states is a critical problem which can possibly arisewith active and passive control. Efficiently transferring and storing the generated broadband or random electric energy is another critical problem for nonlinear PHEs. Moreover, the authors reviewed different designs strategies, optimization techniques, and the harvesting of piezo-materials in applications such as shoes, pacemakers, tire pressure monitoring systems, and bridge and building monitoring systems. They declared that high energy conversion efficiency, ease of implementation, and miniaturization are the main advantages of such systems. However, the authors stated that the enhancement of the energy efficiency of piezo-based harvesters is still an open challenge. They also conducted a systematic performance comparison of some of these energy harvesters. They pointed out that a considerable gap exists between the achieved performance and the expected performance. Therefore, in situ testing, applying more realistic excitations and system-level investigations on piezo-harvesters integrated with power conditioning circuits, energy storage elements, sensors, and control circuits need to be investigated. This article focused on the mechanical part of energy harvesters and subjects such as the electric interface circuits of the harvesters and their energy flow analysis were not remarked upon.

There are some other review papers which have focused on several issues in the design of piezoelectric harvesters. Performance improvement techniques for PHEs and design optimization methods are hot topics covered by several reviews [16,27,31]. Manual and autonomous tuning systems aiming to widen the operating frequency bandwidth, as well as future plans in this field, were discussed by Ibrahim and Vahied [32]. A good review of PEH configurations, such as cantilever beam, discs, cymbals, diaphragms, circular diaphragms, shell-type designs, and ribbon geometries, may be found in [16]. Talib et al. [33] explained effective strategies and key factors in enhancing the performance of piezoelectric energy harvesters operating at low frequencies, including the selection of the piezoelectric material; the optimization of the shape, size, and structure; and the development of multi-modal, nonlinear, multi-directional, and hybrid energy harvesting systems. This review paper is suitable for beginners who want to get acquainted with piezoelectric materials and some designs of piezoelectric energy harvesters. They concluded that recent developments have been inclined towards the generation of more power from low-frequency and lowamplitude ambient vibrations with a reduced amount piezoelectric material required. Adding a single DOF system in the form of an extension beam or a spring to the piezoelectric beam is a remarkable piece of advice in relation to enhancing the power output. The authors showed that the multi-modal energy harvester exhibits a broader bandwidth as its multiple resonance peaks get closer.

\subsection{Electric Interface Circuits}

Brenes et al. [34] provided an overview of existing energy harvesting circuits and techniques for piezoelectric energy scavenging to distinguish between similar existing solutions that are different in practice. Such a categorization is helpful in order to ponder the advantages and drawbacks of each available item. Their review is unique since they classified the piezo-systems based on adaptive/non-adaptive control strategies, topologies, architectures, techniques on the one hand, and electromechanical models on the other hand. The best system was introduced with respect to the optimized power efficiency, the design complexity, the strength of coupling, the multi-stage load adaption, and the vibration frequency.

Issues such as the AC-DC conversion mechanism, the passive and active rectifications, start-up issues, harvester-specific interactions, voltage conditioning, DC-DC charge pumps, 
power regulation, and impedance matching were discussed by Szarka et al. [35] and Dell'Anna et al. [36]. Non-linear electronic interfaces for energy harvesting from mechanical vibrations were discussed in [37].

Tables 3 and 4 gather together the results of evaluation of the review papers written on design methods and the power interface considerations, respectively. The table also contains different sub-categories, the range of output power, the number of reviewed articles, the merits, general conclusions, and some other descriptions. The ranking of each paper was computed based on the number of merits, the number of subcategories, the number of concluding remarks, and with a clear emphasis on value of the minimum required output power.

The results of the evaluation of review papers on the design of piezoelectric energy harvesting have been presented in Table 3. The table also contains different sub-categories, the range of output power, the number of reviewed articles, the merits, general conclusions, and some other descriptions. The grade for each paper was computed based on the number of merits, the number of subcategories, the number of concluding remarks, and the declaration of the minimum required output power. Table 3 is designed to evaluate the review papers on the design of PHEs. The merits that were selected as the necessary considerations in the field of design of PHEs were-1: reporting the output power of PHEs, 2: reporting the coupling factors and operational modes, 3: including mathematical models, 4: attending to the motivating frequencies of PHEs, 5: attending to the mechanical and electrical energy conversion efficiencies. The quantitative evaluation of the papers was performed based on the number of merits which were followed by the article, number of sub-categories which were covered in the review and the number of conclusions. According to the table, with the exception of the first papers, the other papers neglected some merits such as the minimum required output power for the harvesters and energy flow analysis. Furthermore, most of the papers did not review some of the issues in the field. The examined subcategories in the field of design are-1: manual frequency tuning, 2: autonomous frequency tuning, 3: multi-frequency systems, 4: nonlinear systems, 5: frequency up-conversion approach, 6: systems with free moving mass, 7: bidirectional and three-directional systems, 8: amplification techniques, 9: piezoelectric materials and their selection criteria, 10: energy conversion efficiency, 11: low-profile piezoelectric harvesters, 12: geometric optimization, 13: mathematical modeling of PHEs, 14: design improvements for piezoelectric cantilevers, 15: piezoelectric cymbal, 16: piezoelectric stack configuration, 17: electrode optimization, 18: performance quantification and comparison strategies, 19: electronic interface and power storage circuits for PHEs, 20: hybrid energy harvesting mechanism.

The following sub-classes have been presented regarding power interface points 1: three phases in energy harvesting process, 2 : mechanical-electrical energy transduction, 3: energy flow analysis, 4: electrical-to-electrical energy transfer, 5: electric impedance matching, 6: electromechanical models of PHEs, 7: requirements for power electronics, 8: stage topologies (1-, 2-, 3-, and 4-stage topologies), 9: nonadaptive control strategies, 10: adaptive control strategies, 11: optimized synchronized electric charge extraction (OSECE) architecture (including classical OSECE and SECPE), 12: synchronized electric charge extraction (SECE) architectures (including PSSECE, tunable SECE, N-SECE, tunable unipolar SECE, and FTSECE) 13: load adaptation architectures (including full bridge (FB), half bridge, and shunt techniques), 14: hybrid SECE (including SICE and SCSECE), 15: synchronized switch harvesting (SSH) architectures (including ESSH, DSSH, P-SSHI, SSHC, and tunable SSHI techniques). 16: performance comparison of harvesting circuits, 17: choice of an adequate circuit, 18: AC-DC conversion and rectification (including conversion with voltage conditioning, passive and active $\mathrm{VM}$, direct $\mathrm{AC}-\mathrm{DC}$ switch-mode converters, piezospecific switched-inductor converters), 19: DC-DC conversion and rectification (including DC-DC charge pumps, DC-DC switch-mode converters) 20: startup issues, 21: power regulation techniques (including optimum resistance and complex impedance matching), 22: rectifiers for resonant PEHs. 


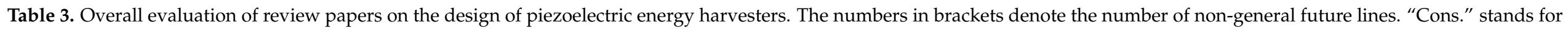

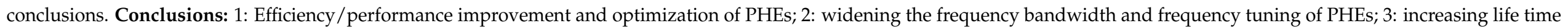

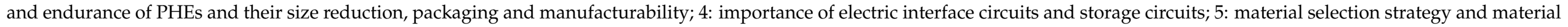

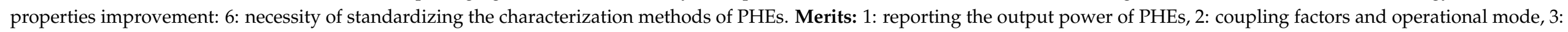

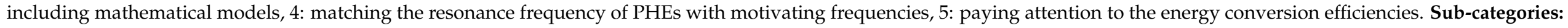
mentioned in the text.

\begin{tabular}{|c|c|c|c|c|c|c|c|}
\hline \# Cons. & $\begin{array}{l}\text { Minimum } \\
\text { Required Output }\end{array}$ & \# Refs. & Merits & Sub-Categories & Ref. & Grade & Highlights \\
\hline $4(0.67)$ & $\mathrm{mW}(1)$ & 35 & $1,2,3,4,5(2)$ & $\begin{array}{l}9,10,11,13,14 \\
15,17,18,19,20 \\
(0.50)\end{array}$ & Uchino [28] & A & $\begin{array}{l}\text { 1: describing the historical background of piezoelectric energy harvesting, } 2 \text { : commenting } \\
\text { on several misconceptions by current researchers, } 3 \text { : step-by-step detailed energy flow } \\
\text { analysis in energy harvesting systems, } 4 \text { : describing the key to dramatic enhancement in } \\
\text { the efficiency, 5: important comments on the useful/non-useful output power level for } \\
\text { the harvesters }\end{array}$ \\
\hline $5(0.83)$ & $\mathrm{mW}(1)$ & 75 & $1,2,3,4,5(2)$ & $\begin{array}{l}9,10,11,13,19 \\
(0.25)\end{array}$ & Priya [29] & $\mathrm{A}$ & $\begin{array}{l}\text { Describing the material selection criteria in on- and off-resonance conditions; describing } \\
\text { the factors which affect the conversion efficiency of PHEs; the introduction of some } \\
\text { low-profile PHEs for the realization of self-powered sensor nodes }\end{array}$ \\
\hline $4(0.67)$ & $\begin{array}{l}\text { microW to } \mathrm{mW} \\
\text { (1) }\end{array}$ & 338 & $1,2,3,4,5(2)$ & $\begin{array}{l}4,12,13,14,15 \\
16,17,18(0.40)\end{array}$ & Yang et al. [30] & $\mathrm{A}$ & $\begin{array}{l}\text { Analysis of different designs, nonlinear methods, optimization techniques, and materials } \\
\text { for increasing performance. Introduction of a set of metrics for the end users of PHEs for } \\
\text { the comparison of the performance of PHEs }\end{array}$ \\
\hline $4(0.67)$ & $\begin{array}{l}\text { microW to } \mathrm{mW} \\
\text { (1) }\end{array}$ & 120 & $1,2,3,4,5(2)$ & $\begin{array}{l}1,5,9,13,14,15 \\
16,19(0.40)\end{array}$ & Li et al. [16] & A & $\begin{array}{l}\text { Commenting on the biggest challenges for PHEs, describing the most important limita- } \\
\text { tions of piezoelectric materials }\end{array}$ \\
\hline $4(0.67)$ & $\begin{array}{l}\text { microW to } \mathrm{mW} \\
\text { (1) }\end{array}$ & 135 & $1,2,4,5(1.6)$ & $\begin{array}{l}4,7,9,12,14,20 \\
(0.30)\end{array}$ & Talib et al. [33] & B & $\begin{array}{l}\text { The authors commented that the anticipated performance of a piezoelectric harvester } \\
\text { can be attained by achieving a trade-off between output power and bandwidth. }\end{array}$ \\
\hline $4(0.67)$ & $\begin{array}{l}\text { microW to } \mathrm{mW} \\
(1)\end{array}$ & 66 & $1,3,4(1.2)$ & $1,2,13(0.15)$ & $\begin{array}{l}\text { Ibrahim and } \\
\text { Vahied. [32] }\end{array}$ & B & $\begin{array}{l}\text { Classifying, reviewing, and comparing different manual and autonomous tuning meth- } \\
\text { ods; meeting the challenge of energy consumption by means of self-tuning structures }\end{array}$ \\
\hline $3(0.50)$ & $\begin{array}{l}\text { microW to } \mathrm{mW} \\
(0)\end{array}$ & 446 & $1,2,3,4,5(2)$ & $\begin{array}{l}3,4,5,7,9,13,14 \\
15,16,20(0.50)\end{array}$ & Liu et al. [21] & B & $\begin{array}{l}\text { Various key aspects to improve the overall performance of a PEH device are discussed. } \\
\text { Classification of performance improvement approaches. }\end{array}$ \\
\hline $2(0.33)$ & $\mathrm{mW}(1)$ & 105 & $1,3,4(1.2)$ & $\begin{array}{l}1,2,3,4,5,6,7 \\
(0.35)\end{array}$ & Yildirim et al. [31] & C & $\begin{array}{l}\text { New classification of performance enhancement techniques. Comparison of many per- } \\
\text { formance enhancement techniques. }\end{array}$ \\
\hline $2(0.33)$ & microW (0) & 149 & $1,3,4,5(1.6)$ & $\begin{array}{l}1,2,3,4,5,6,7,9 \\
(0.40)\end{array}$ & Maamer et al. [27] & $\mathrm{C}$ & $\begin{array}{l}\text { Proposal of a new generic categorization, using an approach based on the improvement } \\
\text { aspects of the harvester, which includes techniques for widening the operating frequency, } \\
\text { conceiving a non-resonant system and multidirectional harvester. Evaluating the appli- } \\
\text { cability of the performance improvement techniques under different conditions and their } \\
\text { compatibility with MEMS technology. }\end{array}$ \\
\hline
\end{tabular}




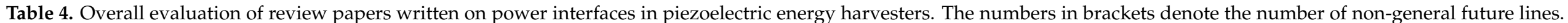

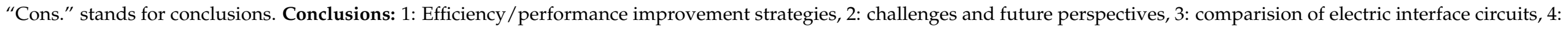

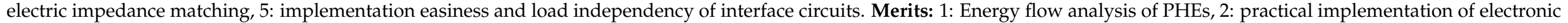

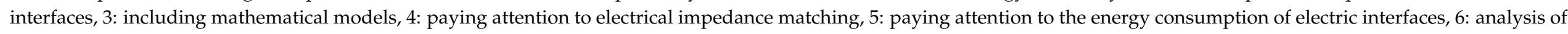
energy conversion efficiency. Sub-categories: mentioned in the text.

\begin{tabular}{|c|c|c|c|c|c|c|c|}
\hline \# Cons. & $\begin{array}{l}\text { Minimum } \\
\text { Required Output }\end{array}$ & \# Refs. & Merits & $\begin{array}{l}\text { Sub- } \\
\text { Categories }\end{array}$ & Ref. & Grade & Highlights \\
\hline $4(0.80)$ & $\mathrm{mW}(1)$ & 35 & $\begin{array}{l}1,2,3,4,5 \\
6(2)\end{array}$ & $\begin{array}{l}1,2,3,4,5,6 \\
7,18,21(0.41)\end{array}$ & Uchino [28] & $\mathrm{A}$ & $\begin{array}{l}\text { The authors report on the minimum acceptable output power for harvesters, energy } \\
\text { flow analysis for a cymbal-type transducer, and a description of the electric impedance } \\
\text { matching technique }\end{array}$ \\
\hline $5(1)$ & microW (1) & 113 & $\begin{array}{l}2,3,4,5,6 \\
(1.67)\end{array}$ & $\begin{array}{l}2,4,5,15,16 \\
18,19,20,21 \\
(0.41)\end{array}$ & Szarka et al. [35] & A & $\begin{array}{l}\text { Overview of power management techniques that aim to maximize the extracted power } \\
\text { of PHEs. Description of the requirements for power electronics, reviewing various } \\
\text { power conditioning techniques and comparing them in terms of complexity, efficiency, } \\
\text { quiescent power consumption, and startup behavior }\end{array}$ \\
\hline $3(0.60)$ & $-(0)$ & 109 & $\begin{array}{l}1,2,3,4,5 \\
6(2)\end{array}$ & 8 to $17(0.45)$ & Brenes et al. [34] & $\mathrm{B}$ & $\begin{array}{l}\text { Comparison of the conditions for electric tuning techniques used to maximize the power } \\
\text { flow from an external vibration source to an electrical load description of necessary } \\
\text { conditions for maximum power point tracking (MPPT) }\end{array}$ \\
\hline $3(0.60)$ & $-(0)$ & 113 & $\begin{array}{l}2,3,4,5,6 \\
(1.67)\end{array}$ & $\begin{array}{l}1,2,4,6,7 \\
15,16,21,22 \\
(0.41)\end{array}$ & Francesco et al. [36] & $\mathrm{C}$ & $\begin{array}{l}\text { 1: Almost all the rectification techniques employed in PEH systems are discussed } \\
\text { and comparedm emphasizing the advantages and disadvantages of each approach. } 2 \text { : } \\
\text { Introducing seven criteria used to evaluate the performance of a harvesting interface }\end{array}$ \\
\hline $2(0.40)$ & $-(0)$ & 64 & $\begin{array}{l}2,3,5,6 \\
(1.33)\end{array}$ & $6,7,20(0.14)$ & $\begin{array}{l}\text { Guyomar and Lal- } \\
\text { lart [37] }\end{array}$ & $\mathrm{D}$ & $\begin{array}{l}\text { 1: review of nonlinear electronic interfaces for energy harvesting from mechanical } \\
\text { vibrations; } 2 \text { : comparative analysis of various switching techniques in terms of efficiency, } \\
\text { performance under several excitation conditions, and complexity of implementation }\end{array}$ \\
\hline
\end{tabular}




\subsection{MEMS/NEMS-Based Devices}

A large number of reviews on piezo-harvesters have been devoted to the field of MEMS/NEMS piezoelectric harvesters. Micro- and nanoscale energy harvesters may be useful in the future for the easy powering or charging of mobile electronics, even in remote areas, without the need for large power storage elements. MEMS-type devices include cantilever, cymbal, and stack designs, whereas NEMS-type devices include wires, rods, fibers, belts, and tubes. The generation of output electric current using piezoelectric energy harvesters faces many limitations and difficulties. Some of these limitations are low output power, high electric impedance, crack propagation in most piezoelectric materials due to overloading, frequency matching of the harvester with vibrational energy sources, and the fabrication/integration of piezoelectrics at the micro-/nanoscale [38].

Kim et al. [39] commented that for the elimination of chemical batteries and complex wiring in microsystems, a fully assembled energy harvester the size of a US quarter dollar coin should be able to generate about $100 \mathrm{microW}$ of continuous power from ambient vibrations. In addition, the cost of the device should be sufficiently low. Their article addresses two important questions: "how can one achieve self-powering when the power required is much larger than what can be achieved by MEMS-scale piezoelectric harvesters?" and "what is the best mechanism for converting mechanical energy into electrical energy at 3-mm dimensions?". Furthermore, they noted that in order to harvest power robustly, the resonance bandwidth of piezoelectric cantilevers should be wide enough to accommodate the uncertain variance of ambient vibrations. Thus, the resonance bandwidth is a significant characteristic in order to trap enough energy in the harvester and should be accounted for in determining the performance of energy harvesters. MEMS technology is a cost-effective fabrication technology for PHEs if it can meet certain requirements for power density and bandwidth. Three major aspects required to make MEMS PEHs appropriate for use in real applications are the final cost of the PEH, the normalized power density, and the operational frequency range (including the bandwidth and center frequency). They added that piezoelectric MEMS energy harvesters most commonly have a unimorph cantilever configuration (Figure 7). The proof mass (M), shown in Figure 7, is used to adjust the resonant frequency to the available environmental frequency, which is normally below $100 \mathrm{~Hz}$. Recently, integrated MEMS energy harvesters have been developed. When comparing MEMS PEHs, some essential merits such as the active area of the PEH, the active volume, resonant frequency, harvested power, and power densities in volume or area should be considered. They reviewed the challenges of piezo-harvesters, including the need for a high power density and wide bandwidth of operation in piezoelectric systems, as well as non-linear resonating beams for wide bandwidth resonance, and improvements in materials and structural design. They observed that the epitaxial growth and grain texturing of piezo-materials, embedded medical systems, lead-free piezoelectric MEMS-based materials, and materials with giant piezoelectric coefficient are active research fields. They presented an extensive comparison of thin-film piezo-systems from various sources and concluded that the state of the art of power density is still about one order smaller than what is needed for practical applications.

Toprak and Tigli [40] conducted a review on piezoelectric harvesters based on their size (nanoscale, microscale, mesoscale, and macroscale). They also presented interesting statistics showing that the number of publications between 2009 and 2014 on piezoelectric harvesting is more than twice the total number of publications about electromagnetic and electrostatic systems. They commented that the inherent reciprocal conversion capability is an important advantage of the piezoelectric energy harvesters, allowing them to have simpler architectures in comparison to their electromagnetic and electrostatic counterparts. They declared that bio-compatibility, the reconciliation with the CMOS technology, rectification and storage losses, and enhancing the operation bandwidth are the most challenging issues in regard to such systems. A discussion on the validity of the classical constitutive 
relations for piezo-materials at the nanoscale and a mention of the minimum required power output of PEHs are missing from this paper.

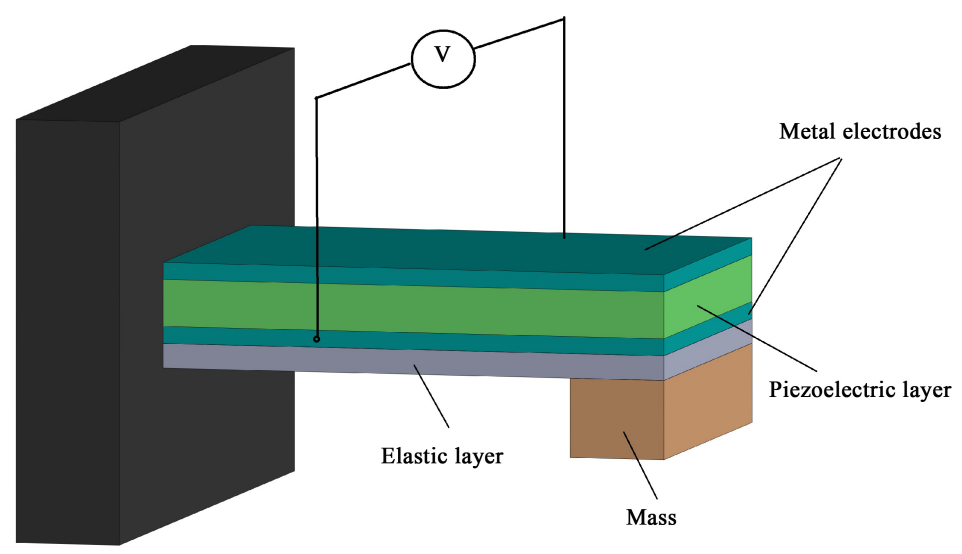

Figure 7. Unimorph structure of a piezoelectric energy harvester that has one piezo-layer and a proof mass [39].

Todaro et al. [41] reviewed the current status of MEMS-based energy harvesters using piezoelectric thin films, and highlighted related approaches and strategies. They commented that such harvesters are compact and cost-effective, especially for harvesting energy from environmental vibrations. They remarked that two main challenges in this topic to achieve high-performance devices involve increasing the amount of generated power and the frequency bandwidth. They also introduced the theoretical principles and the main figures of merit for energy conversion in piezoelectric thin films. They compared most important thin-film piezo-materials based on the introduced figures of merit. Their recommendations for future research include the development of proper materials, new device architectures, and strategies involving bimorph and multimorph designs; exploiting them for their bandwidth and power density improvements; ensuring progress in synthesis and growth technologies for lead-free high quality piezoelectrics; the employment of new flexible materials with tailored mechanical properties for larger displacement and lower frequencies; and taking advantage of non-linear effects to obtain a wider bandwidth and a higher efficiency. Specification of the minimum required output power and attention to mechanical and electrical energy conversion efficiencies were missing from this review paper.

Dutoit et al. focused on design considerations for piezoelectric-based energy harvesters for MEMS-scale sensors. They stated that a power consumption of tens to hundreds of microW is predicted for sensor nodes and nowadays the milli-scale commercial node has an average power consumption of 6-300 microW [2]. With the reduction of power requirements for sensor nodes, the application of piezoelectric energy harvesters has become viable. They stated that power or energy sources can be divided into two groups: sources with a fixed energy density (e.g., batteries) and sources with a fixed power density (normally ambient energy harvesters). They suggested that the following information be made available in research papers to facilitate a relative comparison of PEH devices: device size, the maximum tip displacement at the maximum power output, the mechanical damping ratio, the electrical load, the device mass, and the input vibration characteristics. Furthermore, in this paper a fully coupled electromechanical model was developed to analyze the response of a piezoelectric energy harvester and the difference in optimization strategies of PEHs in on-resonant and off-resonant conditions were remarked upon.

Other review papers on MEMS PEHs have focused on several issues- $\mathrm{ZnO}$ nonorods and flexible substrates and ZnO-based nano-devices [42]; the comparison of existing piezoelectric micro generators (including impact-coupled, resonant and human-powered devices, and the cantilever-based setup) with electromagnetic and electrostatic mechanisms [43]; the description of micro- and nanodevice fabrication techniques, performance 
metrics, and device characterization [14]; hybrid electromagnetic-piezoelectric and triboelectric/piezoelectric MEMS-based harvesters and their privileges [44]; $\mathrm{ZnO}$ nanostructurebased photovoltaics; piezoelectric nano-generators, and the hybrid approach to the harvesting of energy [45]; the benefits, capacities, applications, challenges, and constraints of micro-power harvesting methods using thermoelectric, thermophotovoltaic, piezoelectric, and microbial fuel cells [38]; the use of nanostructured polymer-based piezoelectric and triboelectric materials as flexible, lightweight, easy/cheap-to-fabricate, lead-free, biocompatible, and robust harvesters [46]; theoretical and experimental characterization methods for predicting and determining the potential output of nano wire-based nanogenerators [47]; reviewing the research progress in the field of piezoelectric nanogenerators and describing their working mechanisms, modeling, and structural design [48]; and, finally, discussing the impact of composition, orientation, and microstructures on piezoelectric properties of perovskite thin films such as PbZr1-xTixO3 (PZT) in applications such as low-voltage radio frequency MEMS switches and resonators, actuators for millimeter-scale robotics, droplet ejectors, energy harvesters for unattended sensors, and medical imaging transducers [49].

Table 5 presents details of our evaluation of reviews on micro-/nanoscale energy harvesting. In summary, almost all review articles discussed some great challenges in the development of MEMS-/NEMS-based piezoelectric harvesters, such as the limited bandwidth and low output power. On the other hand, there are some competitive technologies such as electromagnetic, thermoelectric, and electrostatic energy harvesting that can be employed for scavenging environmental waste energy. Most of the comparative review papers have focused on the output power and coupling coefficient of the harvesting systems, and other important features such as the lifetime, capability of working in harsh environmental conditions, the cost level, commercial accessibility, and the technology readiness level (TRL) require more deep considerations.

Subcategories are 1: micro-/nanoscale materials (such as grain textured and epitaxial piezoelectric films, lead-free piezoelectric films, aluminum nitride piezoelectric film, piezoelectric nanopolymers, polymer-ceramic nanocomposite, electrospun $\mathrm{P}(\mathrm{VDF}-\mathrm{TrFE})$ nanofibers, nylon nanowire, template-grown poly-L-lactic acid, electrospun poly-L-lactic acid nanofibers, $\mathrm{ZnO}$-polymer nanocomposite, $\mathrm{ZnO}$ nano-rods, nanowire- and nanowirecomposites, PZT thin films, piezo-polymer thin films, piezoelectric electroactive polymers); 2: nonlinear resonance-based energy harvesting structures; 3 : energy conversion efficiency; 4: figure of merit for MEMS PHEs; 5: material synthesis and deposition (such as solution phase synthesis, thin film deposition, growth of polymer-based nanowires); 6: modes of operations for MEMS PHEs; 7: design configurations for MEMS PHEs (such as cantileverbased piezoelectric generators or other types of piezoelectric generators); 8: microscale PHEs; 9: substrate and electrodes and their impact on performance; 10: MEMS device performance parameters; 11: characterization of MEMS PHEs; 12: MEMS hybrid harvesters (which may include architectures of hybrid harvesters, mathematical models of PZT hybrid harvesters and PZT-tribo-electric hybrid harvesters); 13: nanoscale PHEs (including their working principles, design, fabrication and implementation of nano-generators, hybrid nano-generators, nano-rod arrays, flexible nano-generators, $\mathrm{ZnO}$ nano-PHEs, applications of nano-generators, flexoelectric enhancement at the nanometer scale, characterization of piezoelectric potential from piezoelectric NWs, prototypes of nanogenerators, prediction of the power output from piezoelectric NWs, vertically aligned nanowire arrays and their fabrication, laterally aligned nanowire arrays and their fabrication); 14: impact coupled devices; 15: human powered piezoelectric generation; 16: evolving technology of miniature power harvesters; 17: positive prospects of micro-scale electricity harvesters; 18 : challenges and constraints of minute-scale energy harvesters; 19: CMOS compatibility; 20: characterization methods for MEMS/NEMS PHEs; 21: bandwidth of PHEs; 22: screening effect; 23: piezoelectric thin films; 24: Modelling of MEMS/NEMS PHEs; 25: application of MEMS/NEMS harvesters. 


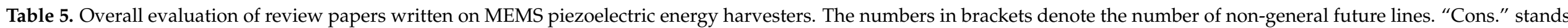

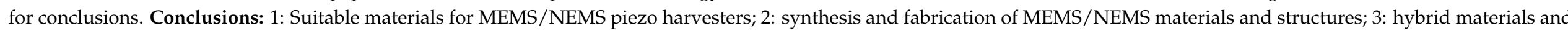

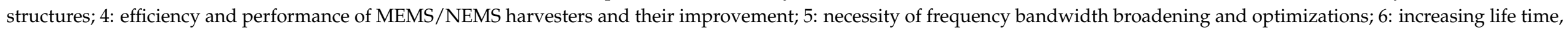

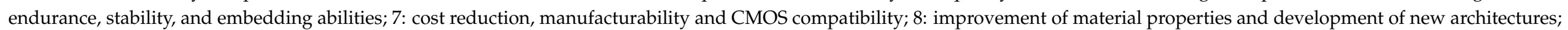

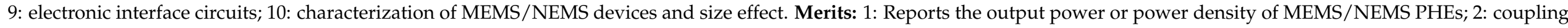

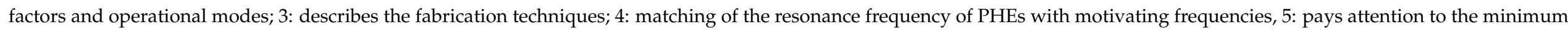
required output power, 6: CMOS compatibility, 7: energy flow analysis. Sub-categories: mentioned in the text.

\begin{tabular}{|c|c|c|c|c|c|c|c|}
\hline \# Cons. & $\begin{array}{l}\text { Minimum } \\
\text { Required Output }\end{array}$ & $\begin{array}{l}\# \\
\text { Refs. }\end{array}$ & Merits & $\begin{array}{l}\text { Sub- } \\
\text { Categories }\end{array}$ & Ref. & Grade & Highlights \\
\hline $8(0.80)$ & microW (1) & 89 & $\begin{array}{l}1,2,3,4,5,6 \\
7(2)\end{array}$ & $\begin{array}{l}1,2,3,4,8,18 \\
(0.24)\end{array}$ & Kim et al. [39] & $\mathrm{A}$ & $\begin{array}{l}\text { Describes figures of merits for MEMS PHEs, mentions the key attributes for MEMS PHEs, describing minimum } \\
\text { acceptable power density for MEMS PHEs }\end{array}$ \\
\hline $7(0.70)$ & microW (1) & 140 & $\begin{array}{l}1,3,4,5 \\
(1.14)\end{array}$ & $\begin{array}{l}1,4,23,25 \\
(0.16)\end{array}$ & Khan [50] & B & $\begin{array}{l}\text { 1: The review covers the available material forms and applications of piezoelectric thin films. 2: The electrome- } \\
\text { chanical properties and performances of piezoelectric films are compared and their suitability for particular } \\
\text { applications is reported. 3: Control over the growth of piezoelectric thin films and lead-free compositions of } \\
\text { thin films can lead to good environmental stability and responses, coupled with higher piezoelectric coupling } \\
\text { coefficients. }\end{array}$ \\
\hline $5(0.50)$ & $\begin{array}{l}\text { microW to } \mathrm{mW} \\
\text { (1) }\end{array}$ & 74 & $\begin{array}{l}1,2,4,5 \\
(1.14)\end{array}$ & $\begin{array}{l}6,7,8,10,23 \\
24(0.24)\end{array}$ & Dutoit et al. [2] & C & $\begin{array}{l}\text { Comments on the necessary information for comparing different PHEs. Points out the differences between } \\
\text { dominant damping components at the micro- vs. macro-scale. Develops a fully coupled electromechanical } \\
\text { model for analyzing the response of PHEs with a cantilever configuration. }\end{array}$ \\
\hline $5(0.50)$ & $\begin{array}{l}\text { microW to } \mathrm{mW} \\
(0)\end{array}$ & 123 & $\begin{array}{l}1,2,3,4,5,6 \\
(1.71)\end{array}$ & $\begin{array}{l}8,13,18,19,21 \\
(0.20)\end{array}$ & $\begin{array}{l}\text { Toprak and } \\
\text { Tigli }[40]\end{array}$ & C & $\begin{array}{l}\text { 1: Notes that size-based classification provides a reliable and effective basis for the study of various piezoelectric } \\
\text { energy harvesters. 2: Discusses the most prominent challenges in piezoelectric energy harvesting and the } \\
\text { studies focusing on these challenges. }\end{array}$ \\
\hline $6(0.60)$ & $\begin{array}{l}\text { microW to } \mathrm{mW} \\
(0)\end{array}$ & 145 & $\begin{array}{l}1,2,3,4,5,6 \\
(1.71)\end{array}$ & $\begin{array}{l}4,8,11,18,21 \\
23(0.24)\end{array}$ & Todaro et al. [41] & C & $\begin{array}{l}\text { 1: Reviews the current status of MEMS energy harvesters based on piezoelectric thin films. 2: The paper } \\
\text { has highlighted approaches/strategies to face the two main challenges to be addressed for high-performance } \\
\text { devices, namely, the generated power and frequency bandwidth. 3: Comparison of several MEMS energy } \\
\text { harvesters' performances. }\end{array}$ \\
\hline $6(0.6)$ & $\begin{array}{l}\text { microW to } \mathrm{mW} \\
(0)\end{array}$ & 108 & $\begin{array}{l}1,2,3,4,5 \\
(1.43)\end{array}$ & $\begin{array}{l}1,5,12,13 \\
(0.16)\end{array}$ & $\begin{array}{l}\text { Jing and Kar- } \\
\text { Narayan [46] }\end{array}$ & C & $\begin{array}{l}\text { 1: Discussion of the growth of nanomaterials, including nanowires of polymers of polyvinylidene fluoride } \\
\text { and its co-polymers, nylon-11, and poly-lactic acid for scalable piezoelectric and triboelectric nanogenerator } \\
\text { applications. 2: Discusses the design and performance of polymer-ceramic nanocomposite. }\end{array}$ \\
\hline $4(0.40)$ & $\begin{array}{l}\text { microW to } \mathrm{mW} \\
(0)\end{array}$ & 115 & $\begin{array}{l}1,2,3,4,5 \\
(1.43)\end{array}$ & $\begin{array}{l}7,14,15,24 \\
(0.16)\end{array}$ & Beeby [43] & $\mathrm{D}$ & Provides a characterization and comparison of piezoelectric, electromagnetic, and electrostatic MEMS generators \\
\hline $4(0.40)$ & $\mathrm{mW}(0)$ & 34 & $\begin{array}{l}1,2,3,4,5 \\
(1.43)\end{array}$ & $12,24(0.08)$ & Salim et al. [44] & $\mathrm{D}$ & $\begin{array}{l}\text { Elaborates on hybrid energy harvesters, reports on the literature on such harvesters for recent years with } \\
\text { different architectures, models, and results, comparing the present hybrid PHEs in terms of output power. }\end{array}$ \\
\hline
\end{tabular}


Table 5. Cont.

\begin{tabular}{|c|c|c|c|c|c|c|c|}
\hline \# Cons. & $\begin{array}{l}\text { Minimum } \\
\text { Required Output }\end{array}$ & $\begin{array}{l}\# \\
\text { Refs. }\end{array}$ & Merits & $\begin{array}{l}\text { Sub- } \\
\text { Categories }\end{array}$ & Ref. & Grade & Highlights \\
\hline $6(0.60)$ & microW $(0)$ & 95 & $\begin{array}{l}1,2,3,4 \\
(1.14)\end{array}$ & $\begin{array}{l}1,13,22,25 \\
(0.16)\end{array}$ & $\begin{array}{l}\text { Briscoe } \\
\text { Dunn }[42]\end{array}$ & $\mathrm{D}$ & $\begin{array}{l}\text { 1: This review summarizes the work to date on nanostructured piezoelectric energy harvesters. 2: The authors } \\
\text { state that in order to satisfy the needs of real power delivery, devices need to maximize the rate of change } \\
\text { of any strain delivered into a system in order to increase the polarization developed by the functional layers, } \\
\text { and improve the coupling of the device to the environment. }\end{array}$ \\
\hline $7(0.70)$ & microW $(0)$ & 78 & $1,2,3(0.86)$ & $\begin{array}{l}1,13,17,18, \\
24,25(0.24)\end{array}$ & Wang et al. [48] & $\mathrm{D}$ & $\begin{array}{l}\text { The working mechanism, modeling, and structure design of piezoelectric nanogenerators are discussed. The } \\
\text { integration of nanogenerators for high output power sources, the structural design for increasing the energy } \\
\text { harvesting efficiency in different conditions, and the development of practicable integrated self-powered } \\
\text { systems with improved stability and reliability are the critical issues in the field classification of nano generators } \\
\text { based on their design and working modes. }\end{array}$ \\
\hline $3(0.30)$ & $-(0)$ & 80 & $\begin{array}{l}1,2,3,4 \\
(1.14)\end{array}$ & $\begin{array}{l}5,6,7,8,9, \\
10,11,20,25 \\
(0.36)\end{array}$ & $\begin{array}{l}\text { Gosavi and Bal- } \\
\text { pande [14] }\end{array}$ & $\mathrm{D}$ & Description of some of the synthesis and deposition techniques and performance parameters for MEMS PHEs \\
\hline $3(0.30)$ & - (0) & 75 & $\begin{array}{l}1,3,4,5 \\
(1.14)\end{array}$ & $1,23,25(0.12)$ & Muralt et al. [49] & $\mathrm{D}$ & $\begin{array}{l}\text { The article has reviewed the impact of composition, orientation, and microstructure on the piezoelectric } \\
\text { properties of perovskite thin films. The author describes useful power levels for MEMS PHEs. }\end{array}$ \\
\hline $5(0.50)$ & microW (0) & 69 & $1,2,4(0.86)$ & $\begin{array}{l}1,13,18,20, \\
24,25(0.24)\end{array}$ & Wang [47] & $\mathrm{D}$ & $\begin{array}{l}\text { 1: Theoretical calculations and experimental characterization methods for predicting or determining the } \\
\text { piezoelectric potential output of NWs are reviewed. 2: Numerical calculation of the energy output from } \\
\text { NW-based NGs. 3: Integration of a large number of ZnO NWs is demonstrated as an effective pathway for } \\
\text { improving the output power. }\end{array}$ \\
\hline $5(0.50)$ & $\mathrm{mW}(0)$ & 112 & $1,4,5(0.86)$ & $\begin{array}{l}3,16,17,18 \\
(0.16)\end{array}$ & $\begin{array}{l}\text { Selvan } \\
\text { Ali }[38]\end{array}$ & $\mathrm{D}$ & $\begin{array}{l}\text { The capabilities and efficiencies off our micro-power harvesting methods including thermoelectric, thermo- } \\
\text { photovoltaic ,piezoelectric, and microbial fuel cell renewable power generators are thoroughly reviewed } \\
\text { and reported }\end{array}$ \\
\hline $3(0.30)$ & $-(0)$ & 100 & $1,3(0.57)$ & $\begin{array}{l}12,13,18,25 \\
(0.16)\end{array}$ & $\begin{array}{l}\text { Kumar } \\
\text { Kim }[45]\end{array}$ & $\mathrm{D}$ & $\begin{array}{l}\text { 1: Description of the mechanism of power generation behavior of nanogenerators fabricated from } \mathrm{ZnO} \text { nanos- } \\
\text { tructures. 2: Describes an innovative and important hybrid approach based on } \mathrm{ZnO} \text { nano-structures. }\end{array}$ \\
\hline
\end{tabular}




\subsection{Modeling Approaches}

Some review papers have focused on the modeling of PHEs to clarify the physical basis behind piezoelectric energy harvesting. There are few review papers that have totally focused on the evaluation of different modeling approaches for piezoelectric energy harvesting.

Erturk and Inman investigated mechanical [51] and mathematical [52] aspects of cantilevered piezoelectric energy harvesters to avoid the reuse of simple and incorrect older models in literature. They reviewed the general solution of the base excitation problem for transverse and longitudinal vibrations of a cantilevered Euler-Bernoulli beam. They proved that the classical single-degree-of-freedom (SODF) predictions may yield highly inaccurate results, and they are only appropriate for high tip-mass-to-beam-mass ratios. Damping due to internal friction (Kelvin-Voigt damping), damping related to the fluid medium, the base excitation as a forcing function, and the backward piezoelectric coupling in the beam equation are among the modeling parameters. The modeling of energy conversion efficiency is missing from the article.

Zhao et al. [53] compared different modeling approaches for harvesting wind energy, including the single-degree-of-freedom, the single-mode, and multi-mode Euler-Bernoulli distributed-parameter models (ignored in Ref. [52]). They concluded that the distributedparameter model has a more rational representation of aerodynamic forces, whereas the SDOF model more precisely predicts the cut-in wind speed and the electro-aeroelastic behavior. In addition, they performed a parametric study on the effect of the load resistance, wind exposure area, mass of the bluff body, and the length of the piezoelectric sheet on the cut-in wind speed, as well as the output power level of the GPEH. Again, the modeling of energy conversion efficiency is missing from the article.

Wei and Jing [54] presented a state-of-the-art review of the theory, modeling, and realization of piezoelectric, electromagnetic, and electrostatic energy harvesters. The linear inertia-based theory and the non-linear models have been described for the three mentioned vibration-to-electricity converters. They investigated some characteristics of the piezoharvesters, such as their being unaffected from external/internal electromagnetic waves, their simple structure, depolarization, the brittleness of the bulk piezo-layer, the poor coupling in piezo-film, and their poor adhesion with the electrode materials. The development of new piezoelectric materials, the creation of new energy harvesting configurations by exploring non-linear benefits and the design of efficient energy harvesting interface circuits are among their suggestions as future prospects. They concluded that the non-linearity is an important and effective parameter in terms of performance enhancement. Theoretical modeling of non-linear systems while maintaining reliability and stability is a challenging task. The reviewed models were not compared in the paper.

Table 6 sums up the results of the evaluation of the review papers written about modeling approaches. The table also contains different sub-categories, the range of output power, the number of reviewed articles, the merits, general conclusions, and some other descriptions. The ranking of each paper was computed based on the number of merits, the number of subcategories, the number of concluding remarks, and with a clear emphasis on value of the minimum required output power. 


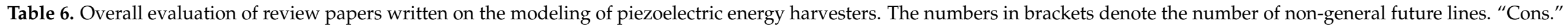

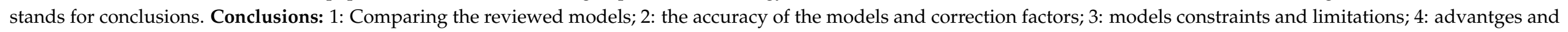

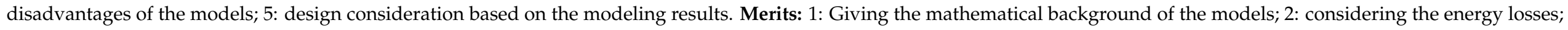

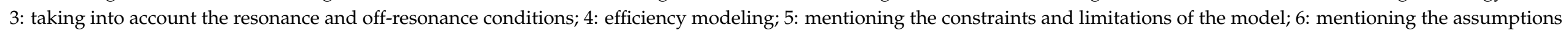

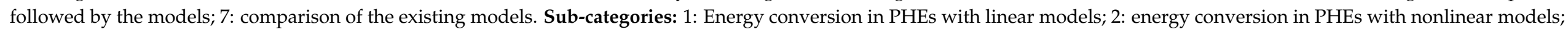

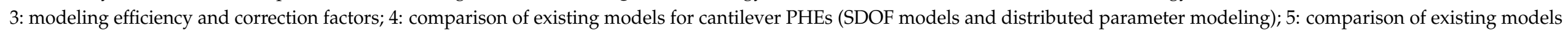

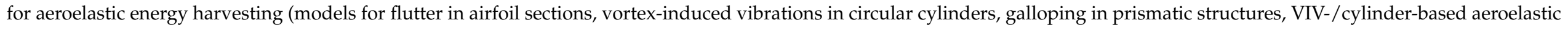
energy harvesters, galloping-based aeroelastic energy harvesters, wake galloping, SDOF models, Euler-Bernoulli distributed parameter model).

\begin{tabular}{|c|c|c|c|c|c|c|c|}
\hline \# Cons. & $\begin{array}{l}\text { Minimum } \\
\text { Required Output }\end{array}$ & \# Refs. & Merits & $\begin{array}{l}\text { Sub- } \\
\text { Categories }\end{array}$ & Ref. & Grade & Highlights \\
\hline $5(1)$ & $\mathrm{mW}(0)$ & 21 & $\begin{array}{l}1,2,3,4,5,6,7 \\
(2)\end{array}$ & $1,3,4(0.60)$ & $\begin{array}{l}\text { Erturk and In- } \\
\text { man }[51,52]\end{array}$ & B & $\begin{array}{l}\text { Issues of the correct formulation for piezoelectric coupling, correct physical modeling, } \\
\text { use of low fidelity models, incorrect base motion }\end{array}$ \\
\hline $4(0.8)$ & $\mathrm{mW}(0)$ & 48 & $\begin{array}{l}1,3,4,5,6,7 \\
(1.71)\end{array}$ & $1,5(0.40)$ & Zhao et al. [53] & $\mathrm{C}$ & $\begin{array}{l}\text { Comparison of the performance of the modeling methods for GPEH, including the } \\
\text { SDOF model, and single mode and multimode Euler-Bernoulli distributed parameter } \\
\text { models. }\end{array}$ \\
\hline $1(0.25)$ & microW (0) & 204 & $1,2,4(0.85)$ & $1,2,3,(0.60)$ & $\begin{array}{l}\text { Wei and } \\
\text { Jing [54] }\end{array}$ & $\mathrm{D}$ & $\begin{array}{l}\text { 1: Review of the energy conversion efficiency of some of the conversion mechanisms; } \\
\text { 2: description of several configuration design for PHEs such as cantilever structures, } \\
\text { and uniform membrane structures. }\end{array}$ \\
\hline $0(0)$ & $\mathrm{mW}(0)$ & 201 & $3,5(0.57)$ & $1,2,5(0.60)$ & Abdelkefi [55] & $\mathrm{D}$ & $\begin{array}{l}\text { Qualitative and quantitative comparisons between existing flow-induced vibrations } \\
\text { energy harvesters, describing some of the limitations of existing models and recom- } \\
\text { mending some improvement for future }\end{array}$ \\
\hline
\end{tabular}




\section{Applications}

Piezo-materials can extract power directly from structural vibrations or other environmental mechanical waste energy sources in infrastructures (bridges, buildings), biomedical systems, healthcare, and medicine. They can also be used as a part of transducers, actuators, and surface acoustic wave devices. In this section, we tried to present a classified review of the contents of existing review papers that have focused on applications involving vibrational sources, waste energy harvesting, fluid-related sources, and biological applications.

\subsection{Vibration}

Vibration is the most common source of energy for piezoelectric harvesters, since there is no need to convert the input energy to the mechanical energy to produce electricity in piezo-materials. Furthermore, its abundance, accessibility, and ubiquity in the environment, in addition to multiple possible transduction types, have made it more attractive for energyharvesting applications. The response of piezoelectric materials to the employed vibrations depends on their electromechanical properties such as the natural frequency, their geometry, the electromechanical coefficients, and the damping characteristics. The design strategies for such types of harvesters, performance enhancement methodologies, the behavior of the energy harvesters in harsh environments, their fatigue life and failure mode, and the conditioning electric circuits are some of the important issues that should be addressed in review papers.

Sodano et al. [56], as one of the earliest reviewers of the field, discussed the future goals that must be achieved for power harvesting systems to find their way towards everyday use, and to generate sufficient energy to power the necessary electronic devices. They mentioned that the major limitations in the field of power harvesting revolve around the fact that the power generated by piezoelectric energy harvesters is far too small to power most electronic devices. Increasing the amount of energy generation, developing innovative methods for accumulating this energy, the use of rechargeable batteries, optimization of the power flow from a piezoelectric setup, minimizing the circuit losses, identifying the location of power harvesting and the excitation range, and proper tuning of the power harvesting device are their predictions for future prospects in regard to vibration-based piezo harvesters. Kim et al. [57] summarized the key ideas behind the performance evaluation of piezoelectric energy harvesters based on vibration, providing classifications, materials, and the mathematical modeling of vibrational energy harvesting devices. They listed 17 important electro-mechanical characteristics of PZT-5H, PZT-8, PVDF, and described various configurations such as the cantilever type, the cymbal type, the stack type, and the shell type. They advised that the future opportunities for research are the development of high coupling coefficients of piezoelectric materials, giving them the ability to sustain harsh vibrations and shocks, the sdevelopment of flexible and resilient piezoelectric materials, and designing efficient electronic circuitry for energy harvesters. Siddique et al. [58] provided a literature review on vibration-based micropower generation using electromagnetic and piezoelectric transduction systems and hybrid configurations. They reported some performance characteristics of piezoelectric energy harvesters with different materials and configurations. They claimed that most of the recent research has been devoted to modifications of the generator size, shape, and to introducing a power conditioning circuit to widen the frequency bandwidth of the system. Further research topics are the development of the MEMS-based energy harvesters from renewable resources and making miniature electric devices more reliable. Figure 8 presents three schematic views of microscale piezo-generators designed for vibration-based energy harvesting applications.

Saadon and Sidek [59] presented a brief discussion of vibration-based MEMS piezoelectric energy harvesters. They summarized various designs of harvesters and reviewed experimental results presented in the 3 years before the date of publication of the paper. 
They focused on the working modes and maximum output power of MEMS piezoelectric energy harvesters.

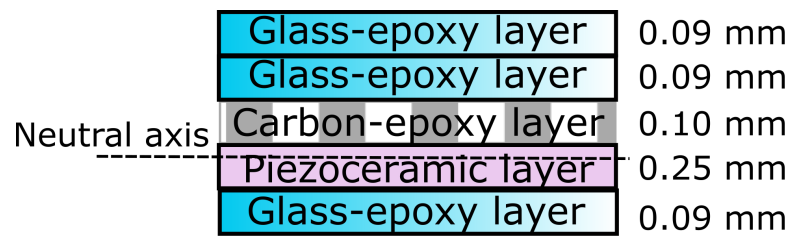

(a)

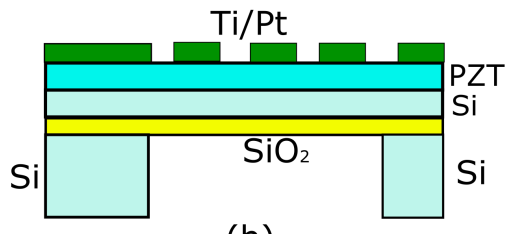

(b)

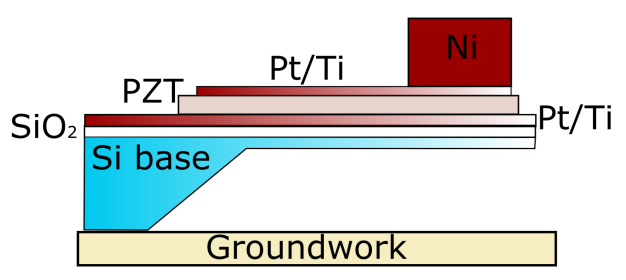

(c)

Figure 8. (a) Geometry and position of the neutral axis of piezocomposite composed of layers of carbon/epoxy, PZT ceramic, and glass/epoxy [57]; (b) a MEMS-based piezo-generator in 3-3 mode [56]; (c) schematic diagram of cross sectional view of a fabricated vibration-based micro power generator [58].

Harb [60] reviewed a brief history of all energy harvesting methods, including the vibration-based, electromagnetic-based, thermal or radioactive-based, pressure-gradientbased, solar- and light-based, biological, and micro-water flow systems. However, it is advised that the different types of vibrations are the most available and the highest power provider sources. Review papers such as the one presented by Zhu et al. [61] are the result of the rapid increase inutilization of vibration-based micro-generators in powering the wireless sensor networks. They demonstrated an overall review of the principles and the operating strategies to increase the operational frequency range of vibrationbased micro-generators. Harne and Wang [62] reported the major efforts and findings about common analytical frameworks and principal results for bi-stable electromechanical dynamics, and a wide variety of bi-stable energy harvesters. Based on their discussion, the remaining challenges of such systems are maintaining high-energy orbits, operation under stochastic vibratory conditions, designing coupled bi-stable harvesters, and defining proper performance metrics.

In summary, different configurations of piezoelectric cantilevers, their power output and performance enhancement strategies have been well covered by review papers. However, a systematic comparison of different configurations of piezoelectric energy harvesters, as well as their ability to sustain harsh vibrations and shocks, their fatigue life, their cost, and accessibility have not been considered by the reviews. Table 7 presents the results of our evaluation of the piezo-electric energy harvesters from vibrational sources. The table also contains different sub-categories, the range of output power, the number of reviewed articles, the merits, general conclusions, and some other descriptions. The ranking of each paper was computed based on the number of merits, the number of subcategories, the number of concluding remarks, and with a clear emphasis on the value of the minimum required output power. 


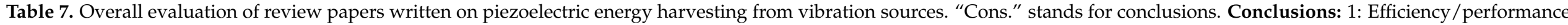

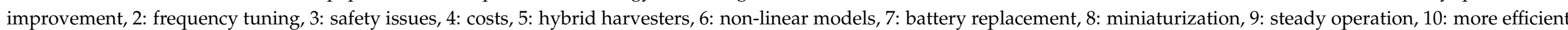

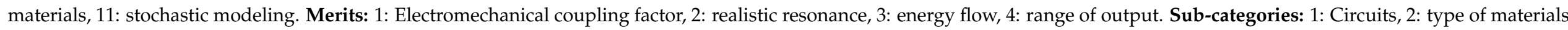
3: modeling, 4: noise level, 5: wearable, 6: frequency range, 7: MEMS.

\begin{tabular}{|c|c|c|c|c|c|c|c|}
\hline \# Cons. & $\begin{array}{l}\text { Minimum } \\
\text { Required Output }\end{array}$ & \# Refs. & Merits & Sub-Categories & Ref. & Grade & Highlights \\
\hline $6(0.55)$ & 0.17 microW (1) & 35 & $2-4(1.5)$ & $1,3,4,5(0.57)$ & Sodano et al. [56] & B & Insufficient output power \\
\hline $3(0.27)$ & microW to $\mathrm{mW}(0)$ & 93 & $1-4(2.0)$ & $1,2,3,5(0.57)$ & Kim et al. [57] & $\mathrm{C}$ & $\begin{array}{l}\text { Comparison with electrostatic and electromagnetic energy con- } \\
\text { versions }\end{array}$ \\
\hline $6(0.55)$ & microW to $\mathrm{mW}(0)$ & 145 & $1-4(2.0)$ & $7(0.14)$ & Siddique et al. [58] & $\mathrm{C}$ & Comparison with electromagnetic and electrostatic \\
\hline $3(0.27)$ & 60 microW (1) & 23 & $2,4(1.0)$ & $1,7(0.29)$ & Saadon and Sidek [59] & $\mathrm{C}$ & Inadequate output power \\
\hline$-(0.0)$ & $2.46 \mathrm{~mW}(1)$ & 56 & $3,4(1.0)$ & $1,6(0.29)$ & Harb [60] & $\mathrm{C}$ & $\begin{array}{l}\text { From thermal sources, RF sources, CMOS devices, and power } \\
\text { management sources }\end{array}$ \\
\hline $7(0.64)$ & $-(0)$ & 50 & $2,3(1.0)$ & $6(0.14)$ & Zhu et al. [61] & $\mathrm{D}$ & Focused on frequency tuning \\
\hline $5(0.46)$ & $-(0)$ & 84 & $1,2(1.0)$ & $2,3(0.29)$ & Harne and Wang [62] & $\mathrm{D}$ & Focused on bistable systems, stochastic vibrations \\
\hline
\end{tabular}




\subsection{Biological Sources}

Biomechanical energy harvesting provides an important alternative to electrical energy for portable electronic devices. Hwang et al. [63] addressed the development of flexible piezoelectric energy-harvesting devices using high-quality perovskite thin films and innovative flexible fabrication processes. In addition, energy harvesting devices with thick and rigid substrates are unsuitable for responding to the movements of internal organs and muscles. The authors noted that the electric power harvested from the bending motion of a flexible thin film is sufficient to stimulate heart muscles. Furthermore, easy bendability, higher conversion efficiency, enhanced sensing capability at the nanoscale, self-energy generation and real-time diagnosis/therapy capabilities are among advantages of such systems. Ali et al. [64] discussed the possibilities of utilizing the piezo-based energy conversion from the source of muscle relaxation and contraction, body movement, blood circulation, lung and cardiac motion in applications such as pacemakers, blood pressure sensors, cardiac sensors, pulse sensors, deep brain simulations, biomimetic artificial hair cells, active pressure sensors, and active strain sensors. Piezoelectric materials containing nanowires, nanorods, nanotubes, nanoparticles, thin films, lead-based ceramics, lead-free ceramics, polymer-based materials, textured polycrystalline materials, and biological piezomaterials have been evaluated. They proposed several challenging problems such as the flexibility to fit into the shape of an organ, the proper management of power, the selection of a media for the electrical connection, enhancing the biological safety, designing the interface between the body tissue and the implanted piezo-material, efficient encapsulation, further miniaturization, and conducting related experiments on small/large animal and human cases.

Surmenev et al. [65] described novel techniques in the fabrication of hybrid piezoelectric polymer-based materials for biomedical energy harvesting applications such as detection of the motion rate of humans, the degradation of organic pollutants, and the sterilization of bacteria. They described the different methods that can be employed for the improvement of the piezoelectric response of polymeric materials and scaffolds. They also reviewed biomedical devices and sensors based on hybrid piezo-composites. Similarly to most other reviews, increasing performance is one of proposed future works. Others are the alignment of nanofiller particles inside the piezopolymer matrix, developing common standards for the consistent quantification and evaluation of the performance of various types of piezoelectric materials, and the investigation of the structural parameters.

The internal charging of implantable medical devices (IMD) is another important biological application of piezoelectric energy harvesting. Extending the lifespan of IMDs and size minimization have become the main challenges for their development. For such devices, energy from body movement, muscle contraction/relaxation, cardiac/lung motions, and blood circulation is used for powering medical devices. Zheng et al. [66] presented an overall review of piezoelectric energy devices in comparison to triboelectric harvesters with the source of body movement, muscle contraction/relaxation, cardiac/lung motions, and blood circulation. They proposed that future opportunities involve the fabrication of intelligent, flexible, stretchable, and fully biodegradable self-powered medical systems for monitoring biological signals, in vivo and in vitro treatment of various diseases, optimization of the output performance, the obtainment of higher sensitivity, elasticity, durability and biocompatibility, biodegradable transient electronics, the intelligent control of dynamic properties in vivo, improvement of operating lifetimes, and absorption efficiency.

The considerable amounts of human energy have opens up the development of energyharvesting technologies for the powering of electronic devices. Riemer and Shapiro [67] investigated the amount of electricity that can be generated from the motion of various parts of the body such as heel strikes, ankles, knees, hips, shoulders, elbows, arms, legs, center-of-mass vertical motion, and body heat emissions, using piezo-harvesters and electrical induction generators. They claimed that such technologies are appropriate for "Third World" countries, which is to some extent doubtful, due to their low performance and the 
high cost of fabrication. Mhetre et al. [68] provided a brief review of micro-energy harvesting techniques and methods from limb movement for drug delivery purposes, dental applications, and body heat recovery using piezoelectric transducers. They announced that the main challenge is to enhance the energy output using proper electronic circuit designs. Much more research is required in order to harvest energy from other biological parameters such as body temperature and respiration. The average amount of energy used by the body is $1.07 \times 10^{7} \mathrm{~J}$ per day. This amount of energy is equivalent to approximately $800 \mathrm{AA}(2500 \mathrm{mAh})$ batteries with a total weight of about $20 \mathrm{~kg}$.

In addition to biocompatibility problems, the main challenges in the development of these types of energy harvesters are constructing a device that can harvest as much energy as possible with minimal interference with the natural function of the body. Furthermore, the device should not increase the amount of energy required by a person to perform his/her activities. Specifically for IMDs, the lifetime and efficient power output of the energy harvesters are of the outmost importance. Figure 9 illustrates the magnitude of harvestable energy sources from the human body organs. Similar values can be predicted more or less from organs of animals in related applications.

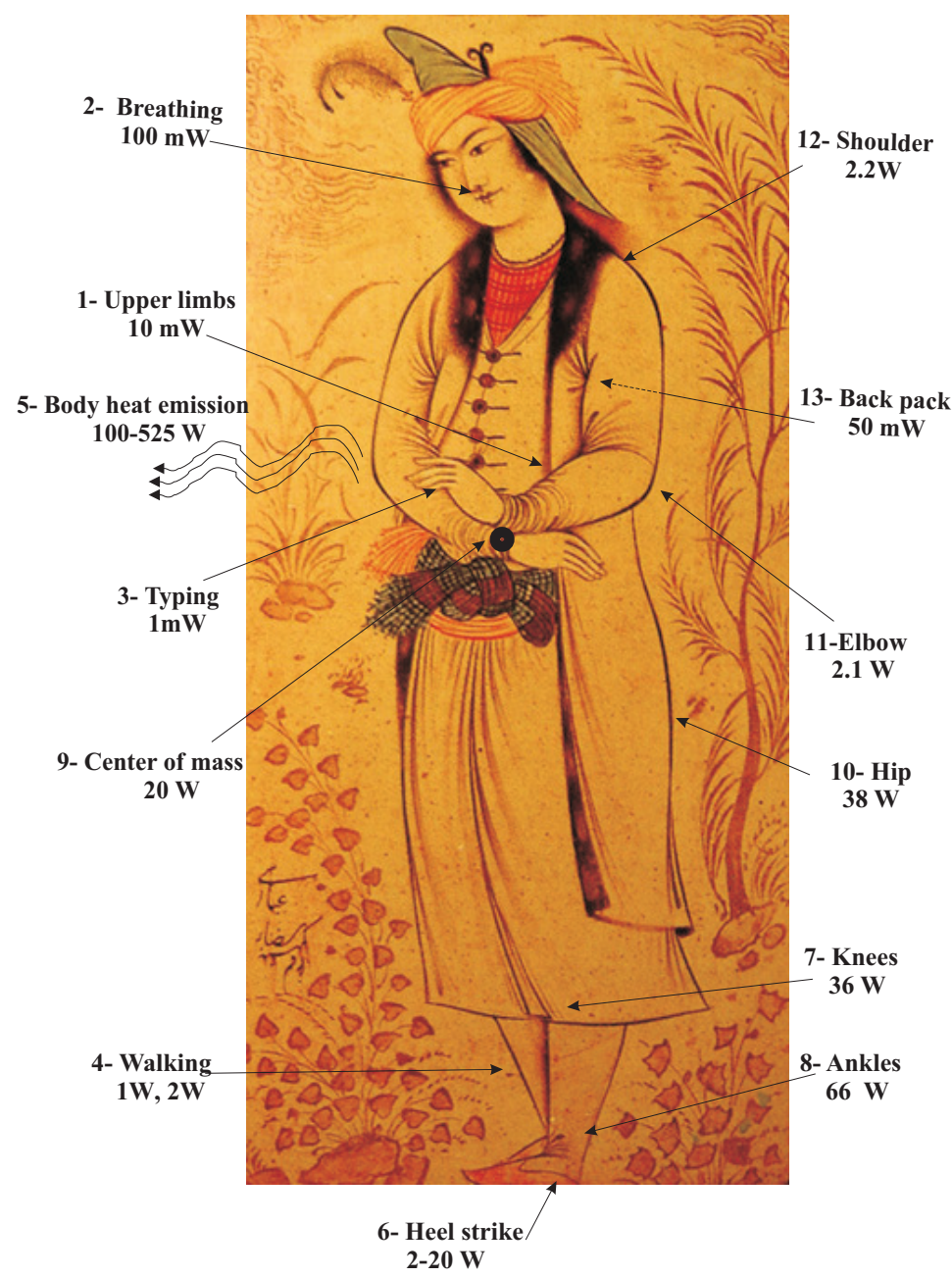

Figure 9. Available sources of energy from organs of the human body. The data numbered 1-4 were obtained from Refs. [9] and those numbered 4-13 from [67]. The results are illustrated on Reza Abbasi's "Prince Muhammad-Beik" drawing (1620, public domain). 
Xin et al. [69] reviewed shoes equipped with piezoelectric energy harvesters. They described the advantages and limitations of the current and newly-developed piezoelectric materials, including flat plate-type, arch-type, cantilever-type, nanocomposite-based, photosensitive-based, and hybrid piezoelectric-semiconductor technologies. They announced that enhancing the coupling coefficient of the piezoelectric materials and optimizing the structure of the energy harvester and the energy storing circuit require further investigation.

The reviewed articles about biological applications have focused on highlighting new materials and structures of biological energy harvesters and their power outputs. The bio-compatibility, the interference of the device with the biological organ, and the reliability of the device, along with its lifetime and economic issues, are open topics in the field. Table 8 summarizes the highlights and descriptions of the review articles related to the biological applications. The grade of each paper was computed based on the number of merits, the number of subcategories, the number of concluding remarks, and with a clear emphasis on the value of the minimum required output power.

Table 8. Overall evaluation of review papers written on piezoelectric energy harvesting from biological applications. "Cons." stands for conclusions. Conclusions: 1: Efficiency/performance improvement, 2: safety issues, 3: costs, 4: hybrid harvesters, 5: non-linear models, 6: battery replacement, 7: miniaturization, 8: steady operation, 9: efficient (flexible, stretchable, bio-compatible) materials, 10: self-powered, 11: wearability, 12: control systems. Merits: 1: electromechanical coupling factor, 2: realistic resonance, 3: energy flow, 4: range of output. Sub-categories: 1: organ motion, 2: heel strike, 3: ankle, 4: Knee, 5: hip, 6: center of mass, 7: arms, 8: muscles, 9: cardiac/lung motion, 10: blood circulation, 11: heat emission, 12: drug delivery, 13: dental cases, 14: thin films, 15: artificial hair cell, 16: biosensors.

\begin{tabular}{llllllll}
\hline \# Cons. & $\begin{array}{l}\text { Minimum } \\
\text { Required Output }\end{array}$ & \# Refs. & Merits & $\begin{array}{l}\text { Sub- } \\
\text { Categories }\end{array}$ & Ref. & Grade & Highlights \\
\hline $5(0.42)$ & $250 \mathrm{~V}, 8.7$ microA (1) & 71 & $1,3,4(1.5)$ & $\begin{array}{l}1,9,14,15 \\
(0.25)\end{array}$ & Hwang et al. [63] & B & Focused on thin films \\
\hline $9(0.75)$ & $11 \mathrm{~V}, 283$ microA (1) & 240 & $1,4(1.0)$ & $\begin{array}{l}1,8,9,10,16 \\
(0.31)\end{array}$ & Ali et al. [64] & B & - \\
\hline $8(0.67)$ & 1 microF, 20 V, 50 s (1) & 235 & $1,4(1.0)$ & $1,16(0.13)$ & Surmenev et al. [65] & C & $\begin{array}{l}\text { Lead-free polymer-based, size-dependent } \\
\text { effects, insufficient output power of piezo- } \\
\text { electric polymers and their copolymers }\end{array}$ \\
\hline $7(0.58)$ & $11 \mathrm{mWcm}{ }^{-3}(1)$ & 107 & $1,4(1.0)$ & $8,9,10(0.19)$ & Zheng et al. [66] & C & Comparison with triboelectric methods \\
\hline $4(0.33)$ & $2 \mathrm{~W}(1)$ & 38 & $4(0.50)$ & $\begin{array}{l}1,2,3,4,5,6, \\
7,11(0.50)\end{array}$ & $\begin{array}{l}\text { Riemer Shapiro [67] } \\
\text { and }\end{array}$ & $\mathrm{C}$ & $\begin{array}{l}\text { Comparison with electrical induction gen- } \\
\text { erators and electroactive polymers }\end{array}$ \\
\hline $1(0.08)$ & $\mathrm{mW}(0)$ & 29 & $4(0.50)$ & $12,13(0.13)$ & Mhetre et al. [68] & D & - \\
\hline $4(0.33)$ & $-(0)$ & 53 & $1(0.50)$ & $1(0.063)$ & Xin et al. [69] & E & Shoe-equipped geometry classification \\
\hline
\end{tabular}

\subsection{Fluids}

Wang et al. [70] categorized fluid-induced vibrations for the purpose of energy harvesting into four categories based on different vibration mechanisms: vortex-induced vibration, galloping, fluttering, and buffeting. They discussed vortex-induced vibrations and buffeting (as forced vibration cases), galloping, and fluttering (as limit-cycle vibration items) using electromagnetic, piezoelectric, electrostatic, dielectric, and triboelectric methods, along with the corresponding numerical and experimental endeavors. They presented a fruitful summary of the current research status on flow-induced vibration hydro/aero energy harvesters. They concluded that the flow pattern around bluff bodies, size limitations, the estimation of the costs of equipment, maintenance costs, the lifespan, the protection of equipment in the case of extreme weather, possible environmental impacts, non-linear modeling, intelligent regulating elements such as artificial neural networks, the implementation of hybrid multi-purpose energy harvesters, and the development of new materials need to be further studied. Figure 10 presents four classes of energy harvesting: vortex-induced vibrations, buffeting, galloping, and fluttering, from vibration mechanisms corresponding to fluid flows [70]. 


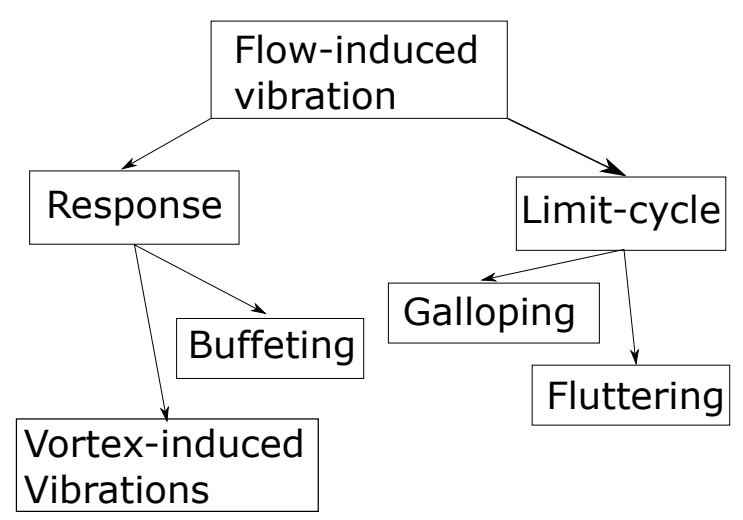

Figure 10. Different classes of energy harvesting categories from flow-induced vibrations [70].

Truitt and Mahmoodi [71] reviewed the effects of wind-based energy harvesting from flow-induced vibrations by bluff bodies and aeroelastic instabilities (fluttering and galloping). They presented an overall study of energy generation density and the peak power outputs versus the bandwidth. After a brief review of the dynamics of piezoelectric energy harvesting, theories and principles, energy densities, and output powers, they concluded that the balance of efficiency-cost-manufacturability is the future horizon of the topic. They suggested the use of PVDFs in fluid excitation applications due to their increased flexibility over PZTs. They concluded that the fluttering- and galloping-based methods generate a higher output power, but with a narrower frequency bandwidth in comparison to vortex-induced methods. Furthermore, the final vision for energy harvesting may be active energy harvesting, in which the system dynamics can actively change in real-time to meet changing environmental dynamics.

Viet et al. [72] compared three energy harvesting methods, including electrostatic, electromagnetic, and piezoelectric technologies to indicate the benefits of piezoelectric harvesting in power generation, transmission, structural installation, and economic cost. Then, they reviewed different design methodologies of harvesting energy from ocean waves. The effects of longitudinal, bending, and shear couplings were discussed. It was concluded that due to higher energy generation density, higher voltage generation capability, simpler configuration, and more economic benefits, piezoelectric technology is superior to other methods.

McCarthy et al. [73] reviewed the research carried out on piezoelectric energy-harvesting based on fluttering. They introduced the mathematical terms needed to define the performance of the fluttering harvester. They discussed the effects of the Strouhal number as a function of the Reynolds number, the wind characteristics, and the formation of the atmospheric boundary layer (ABL). They declared that ultra-low power densities, the long return period of investments, and the quantification and alleviation of fatigue damage are the main challenges for fluttering-energy-harvesting. Based on their conclusions, determining the fatigue life and some metrics for piezoelectric flutter, weather, and precipitation effects are active research fields.

Hamlehdar et al. [74] presented a review of energy harvesting from fluid flows. Despite the general topic of the paper, piezo-energy harvesting from blood as a liquid was ignored. They performed a literature review on energy production from vortex-induced vibration, the Karman vortex street, flutter-induced motion, galloping, and waves with water and air as working fluids. Furthermore, there is a short discussion of modeling challenges. The results of the review conducted by Wong et al. [75] imply that piezoelectric energy harvesting from rain drops has benefits such as a simple structure, ease of fabrication, a reduced number of components, and the direct conversion of vibrational energy to electrical charge.

Elahi et al. [76] studied the fluid-structure interaction-based, human-based, and vibration-based energy harvesting mechanisms by qualitatively and quantitatively analyzing the existing piezoelectric mechanisms. They reviewed the vortex-induced vibra- 
tion, fluttering, galloping, and human-related structures. They noted that a significant amount of research has been conducted on aeroelastic energy harvesters, but aerodynamic models can be improved by taking into account steady, quasi-steady, and unsteady aerodynamics. They stated that the main challenge in this field is to design and optimize raindrop harvesters for outdoor uses, which are resistant against sunlight, wind, the impact force of larger drops, waterproof, which show appropriate sensitivity to drops, which supply constant-rate energy over long periods of time, and which optimize power efficiency. Chua et al. [77] reviewed different types of raindrop kinetic energy piezoelectric harvesters, including the bridge structure; the cantilever structure with the impact point near the free-end; the cantilever structure with six impact points at varies surface locations; the cantilever structure with the impact point at the center; the PVDF membrane or the PZT edge-anchored plate; and collecting diaphragm cantilevers. They also presented a brief summary of the characteristics of hybrid harvesters. It is stated that the best parameter for the comparison of different harvesters is the efficiency rather than the output peak power. Therefore, based on this criterion, it was found that the cantilever-type and the bridge-type energy harvesters made of PZT are the best choices. This is to some extent in contrast to the recommendations of Wong et al. [75].

Table 9 presents the details and highlights of review papers on fluid-based piezoenergy harvesting. The grade of each paper was computed based on the number of merits, the number of subcategories, the number of concluding remarks, and with a clear emphasis on the value of the minimum required output power.

Table 9. Overall evaluation of review papers written on piezoelectric energy harvesting from fluids. The numbers in parentheses denote number of non-general future lines. "Cons." stands for conclusions. Conclusions: 1: Efficiency/performance improvement, 2: frequency tuning, 3: safety issues, 4: costs, 5: hybrid harvesters, 6: non-linear models, 7: battery replacement, 8: miniaturization, 9: steady operation, 10: more efficient materials. Merits: 1: electromechanical coupling factor, 2: realistic resonance, 3: energy flow, 4: range of output. Sub-categories: 1: water waves, 2: galloping, 3: fluttering, 4: buffeting, 5: modelling, 6: wind's vortex street, 7: instabilities, 8: raindrop, 9: mechanical design.

\begin{tabular}{|c|c|c|c|c|c|c|c|}
\hline \# Cons. & $\begin{array}{l}\text { Minimum } \\
\text { Required Output }\end{array}$ & \# Refs. & Merits & $\begin{array}{l}\text { Sub- } \\
\text { Categories }\end{array}$ & Ref. & Grade & Highlights \\
\hline $9(0.9)$ & $>0.0289 \mathrm{~mW}(1)$ & 125 & $1,2,3,4(2.0)$ & $\begin{array}{l}1,2,3,4 \\
(0.44)\end{array}$ & Wang et al. [70] & A & Internet of things, machine learning tools \\
\hline $4(0.4)$ & $115 \mathrm{~mW}(1)$ & 62 & $12,3,4(2.0)$ & $\begin{array}{lll}2, \quad 3, & 6, & 7 \\
(0.44) & & \end{array}$ & $\begin{array}{l}\text { Truitt and Mah- } \\
\text { moodi [71] }\end{array}$ & B & Active control theory \\
\hline $4(0.4)$ & 116 microW $/ \mathrm{cm}^{3}(1)$ & 96 & $1,2,4(1.5)$ & $1,9(0.22)$ & Viet et al. [72] & B & - \\
\hline $5(0.5)$ & $440 \mathrm{microW} / \mathrm{cm}^{3}(1)$ & 96 & $2,4(1.0)$ & $3,6,9(0.33)$ & McCarthy et al. [73] & $\mathrm{C}$ & $\begin{array}{l}\text { Noise level, atmospheric boundary layer, } \\
\text { fatigue life }\end{array}$ \\
\hline $5(0.5)$ & $>1$ microW $(1)$ & 199 & $4(0.50)$ & $\begin{array}{l}1,2,5,6,7 \\
(0.56)\end{array}$ & Hamlehdar et al. [74] & $\mathrm{C}$ & Biomimetic design \\
\hline $4(0.4)$ & $-(0)$ & 87 & $1,3,4(1.5)$ & $8(0.11)$ & Wong et al. [75] & $\mathrm{C}$ & Size effects \\
\hline $5(0.5)$ & $\mathrm{nW}$ to $\mathrm{mW}(0)$ & 256 & $1,4(1.0)$ & $2,3,6(0.33)$ & Elahi et al. [76] & $\mathrm{D}$ & Human-based sources \\
\hline $4(0.4)$ & microW $(0)$ & 73 & $4(0.50)$ & $8(0.11)$ & Chua et al. [77] & $\mathrm{D}$ & Circuit design, hydrophilic surface \\
\hline
\end{tabular}

\subsection{Ambient Waste Energy Sources}

Guo and $\mathrm{Lu}$ [78] discussed recent advances in the application of thermoelectric and piezoelectric energy harvesting technologies from pavements. They found that a pipe system cooperating with a thermoelectric generator is superior in terms of cost effectiveness and electricity output to piezoelectric transducers (fabricated with PZT). Based on their recommendations, the impact of the mentioned energy harvesting facilities on pavement performance, life-cycle assessments, optimization with respect to traffic conditions and solar radiation, and the change in vehicle fuel consumption due to additional vehicle vibration or resistance should be evaluated in future works. Duarte and Ferreira [79] presented a comparative study of photovoltaic, thermoelectric, electromagnetic, hydraulic, pneumatic, electromechanical, and piezoelectric harvesting technologies. Their evaluation 
parameters were the conversion efficiency, the maximum generated power, the installation method, and TRL. They declared that the essential economic data for these products were not yet available. Wang et al. [80] illustrated the applications of photovoltaic cells, solar collectors, geothermal, thermoelectric, electromagnetic, and piezoelectric energy extraction systems from bridges and roads in terms of energy output, benefit-cost ratio, and the technological readiness level.

Based on their conclusions, the grade of support for piezoelectric harvesters by governments is low to medium, whereas solar and geothermal systems are being strongly supported. Pillai and Deenadayalan [81] presented a review of acoustic energy harvesting methods and piezoelectricity as a promising technology in this category due to its sensitivity and efficiency at high frequency excitations.

They declared that the optimization of the resonator and the coupling of thermoacoustic engine to the acoustic-electricity conversion transducer are open research fields. Khan and Izhar [82] reviewed the recent developments in the field of electromagnetic- and piezoelectric-based acoustic energy harvesting. They reported on the sound pressure levels of various ambient acoustic energy sources. A set of useful data about the sound pressure level $(\mathrm{dB})$ and the frequency of various acoustic energy sources has been reported. They reported that researchers were focusing on enhancing the performance of the piezoelectric membrane through novel fabrications and optimized geometrical configurations. Duarte and Ferreira [83] conducted a comparative study on road pavement energy harvesting technologies. They compared existing technologies based on the installed power (per area or volume), the conversion efficiency, and the power density. Furthermore, they classified the harvesting technologies based on their technology readiness level (TRL) values. They demonstrated that the piezoelectric technology was at a high TRL. However, it delivered an insufficient energy production rate, with low economic characteristics.

In addition, some of previously discussed papers devoted a part of their review to piezo-based energy harvesting from waste energies. The performance of electromagneticand piezoelectric-based vibration energy harvesters for energy production from bridges was evaluated by Khan and Ahmad [23]. They expressed that the majority of current harvesters are constructed based on the electromagnetic effect, but piezo-materials are commercially available and are easy to develop. The resonant frequency is a critical parameter in such narrow-band low-frequency applications, which is a benefit of electromagnetic systems. Maghsoudi Nia et al. [24] presented different technologies for converting the kinetic energy of the human body during walking to electricity by locating a harvesting system on the body or inserting a harvester in the floor.

In contrast to the results of Guo and $\mathrm{Lu}$ [78], it was recommended that the piezoelectric harvester is a better choice for such applications, due to its simplicity and flexibility, regardless of its lower power output. Yildirim et al. [31] reviewed amplification techniques, resonance tuning methods, and non-linear oscillations in applications involving ambient vibration harvesting, based on piezoelectric, electrostatic, and electromagnetic conversion methods. Al-Yafeai et al. [84] reviewed methodologies to convert the dissipated energy in the suspension dampers of a car to electricity, along with discussing the mathematical car models and respective experimental setups. The disadvantages of the piezo-generator in comparison to other methods were poor coupling, high output impedance, charge leakage, and the low output current. However, the advantages were its simple structure, the lack of a need for external voltage sources and mechanical constraints, compatibility with MEMSbased devices, high output power, and its wide frequency range. Dagdeviren et al. [85] highlighted the essential mechanical-to-electrical conversion processes and the key design considerations for flexible and stretchable piezoelectric energy harvesters appropriate for soft tissues of the human body, smart robots, and metrology tools. They declared that the development outlooks of such devices are related to designs and fabrication techniques.

Table 10 presents details and highlights of the review papers on ambient and waste energy piezo-harvesting methods. The grade of each paper was computed based on the 
number of merits, the number of subcategories, the number of concluding remarks, and with a clear emphasis on the value of the minimum required output power.

Table 10. Overall evaluation of review papers written on piezoelectric energy harvesting from waste energies. "Cons." stands for conclusions. Conclusions: 1: Efficiency/performance improvement and optimization, 2: safety issues, 3: costs, 4: hybrid harvesters, 5: non-linear models, 6: battery replacement, 7: miniaturization, 8: steady operation, 9: efficient materials, 10: control systems. Merits: 1: electromechanical coupling factor, 2: realistic resonance, 3: energy flow, 4: range of output. Sub-categories: 1: acoustic energy, 2: modelling, 3: road pavement, 4: railway, 5: bridge.

\begin{tabular}{|c|c|c|c|c|c|c|c|}
\hline \# Cons. & $\begin{array}{l}\text { Minimum } \\
\text { Required Output }\end{array}$ & \# Refs. & Merits & $\begin{array}{l}\text { Sub- } \\
\text { Categories }\end{array}$ & Ref. & Grade & Highlights \\
\hline $4(0.4)$ & $241 \mathrm{Wh} / \mathrm{y}(1)$ & 120 & $3,4(1.0)$ & $3,5(0.40)$ & Wang et al. [80] & $\mathrm{C}$ & $\begin{array}{l}\text { Comparison with photovoltaic cell, solar } \\
\text { collector, geothermal, thermoelectric, elec- } \\
\text { tromagnetic devices, fatigue failure and } \\
\text { life-cycle }\end{array}$ \\
\hline $4(0.4)$ & $100 \mathrm{~mW}(1)$ & 65 & $3,4(1.0)$ & $2,3(0.40)$ & Guo and $\mathrm{Lu}[78]$ & C & Comparison with thermoelectrics \\
\hline $4(0.4)$ & $10-100 \mathrm{~W}(1)$ & 34 & $3,4(1.0)$ & $4(0.20)$ & $\begin{array}{l}\text { Duarte and Fer- } \\
\text { reira [79] }\end{array}$ & $\mathrm{C}$ & $\begin{array}{l}\text { Comparison with electromagnetic devices, } \\
\text { TRL level presented }\end{array}$ \\
\hline $3(0.3)$ & $-(0)$ & 80 & $2,4(1.0)$ & $1,2(0.40)$ & $\begin{array}{l}\text { Pillai and Deena- } \\
\text { dayalan [81] }\end{array}$ & $\mathrm{D}$ & Comparison with thermo-acoustics \\
\hline $2(0.2)$ & $-(0)$ & 54 & $2,4(1.0)$ & $1(0.20)$ & $\begin{array}{l}\text { Khan } \quad \text { and } \\
\text { Izhar [82] }\end{array}$ & $\mathrm{D}$ & Comparison with electromagnetics \\
\hline $2(0.2)$ & $-(0)$ & 97 & $4(0.50)$ & $3(0.20)$ & $\begin{array}{l}\text { Duarte and Fer- } \\
\text { reira [83] }\end{array}$ & $\mathrm{E}$ & $\begin{array}{l}\text { Comparison with solar, thermoelectric, } \\
\text { and electromagnetic devices }\end{array}$ \\
\hline
\end{tabular}

\section{Challenges for Future Research}

Table 11 illustrates the number of published review papers in each field, the year of the first and the last published review papers, and the studies' funding sources. It is obvious that energy-harvesting from ambient energies, MEMS/NEMS, and fluid-based harvesting, as well as material considerations, respectively, have the highest rate of publication of review papers. The numbers in brackets demonstrate the number of funded review papers. Although it is predictable that some supporters prefer to remain anonymous, it is seen that about $46 \%$ of papers have been supported by a non-university organization. The last column of the table presents a list of organizations and respected countries that have devoted full/partial financial support to the review papers on piezo-materials.

It is expected that forthcoming review papers will focus on specialized topics. However, they may still contain some degree of generality. Due to the multidisciplinary nature of the field, it is vital to publish comprehensive reviews on detailed aspects of piezoelectric harvesters. The publication of review papers on general topics is not welcomed anymore. The rate of publication of review papers on biological topics is less than expected. Due to the rapid progress of piezoelectricity in biomedical engineering, increasing the number of reviews in related fields is inevitable. We suggest that researchers should present some state-of-the-art articles with specific topics, including progress in piezoelectric materials, new applications of piezoelectric energy harvesters, and new developments in MEMS and NEMS piezoelectric harvesters.

The results of comparative studies on energy harvesters for railways demonstrated that, even in macroscale energy harvesting, piezoelectric energy harvesters are not very successful with respect to other harvesting technologies. This situation may be worse for micro- and nanoscale harvesters. We predict that single (non-hybrid) piezoelectric energy harvesters would be the optimal choice only in some specific applications for which other harvesting systems have inherent limitations. Thus, there is an essential need for fair comparisons of all types of energy harvesters for specific applications. On the other hand, we encountered a growing number of publications on piezoelectric energy harvesters. It should be noted that the real world selects energy-harvesting systems with higher performances and lower costs. 


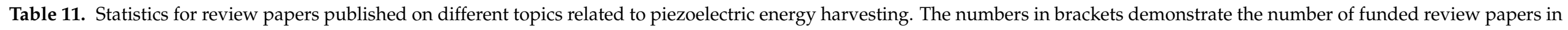
each field.

\begin{tabular}{|c|c|c|c|c|c|}
\hline & Topic & \#Reviews & Period & \# Reviews per Year & Non-University Research Fund Sources \\
\hline 1 & General & $8(4)$ & 2005-2019 & 0.53 & $\begin{array}{l}\text { National Science Foundation (USA), National Natural Science Foundation (China), Spanish Ministry of Science and Technology and } \\
\text { the Regional European Development Funds (European Union), NanoBioTouch European project/Telecom Italia/Scuola Superiore } \\
\text { SantAnna (Italy). }\end{array}$ \\
\hline 3 & Material & $11(7)$ & 2009-2019 & 1.00 & $\begin{array}{l}\text { M/s Bharat Electronics Limited (India), National Nature Science Foundation (China), Office of Basic Energy Sciences, Department } \\
\text { of Energy (USA)/Center for Integrated Smart Sensors funded by the Korea Ministry of Science (Korea), National Natural Science } \\
\text { Foundation (China)/Shanghai Municipal Education Commission and Shanghai Education Development Foundation (China), } \\
\text { European Research Council/European Metrology Research Programme/ UK National Measurement System, National Natural } \\
\text { Science Foundation (China), China scholarship Council/China Ministry of Education/Institute of sound and vibration }\end{array}$ \\
\hline 4 & Modeling & $5(3)$ & 2008-2017 & 0.5 & Air Force Office of Scientific Research (USA), Air Force Office of Scientific Research (USA), a NSFC project of China \\
\hline 5 & Vibration & $8(1)$ & 2004-2015 & 0.67 & Energy Efficiency \& Resources of the Korea Institute of Energy Technology Evaluation/Creative Research Initiatives \\
\hline 6 & Biology & $6(5)$ & 2011-2019 & 0.67 & $\begin{array}{l}\text { Russian Science Foundation/Alexander von Humboldt Foundation/European Commission, National Key R\&D Project from } \\
\text { Minister of Science and Technology (China), Basic Science Research Program (Korea)/Center for Integrated Smart Sensors as Global } \\
\text { Frontier Project, R\&D Center for Green Patrol Technologies through the R\&D for Global Top Environmental Technologies program } \\
\text { funded by the Korean Ministry of Environment, Paul Ivanier Center for Robotics and Manufacturing Research/Pearlstone Center } \\
\text { for Aeronautics Research }\end{array}$ \\
\hline 7 & Sensors & $5(4)$ & 2007-2016 & 0.5 & $\begin{array}{l}\text { Spanish Ministry of Education and Science, NSSEFF/fellowship/ NSF/ Ben Franklin Technology PArtners/the Center for Dielectric } \\
\text { Studies / ARO/DARPA/the Materials Research Institute/U.S Army Research Laboratory, Converging Research Center Program } \\
\text { by the Ministry of Education Science and Technology (Korea), Basic Science Research Program through the National Research } \\
\text { Foundation of Korea }\end{array}$ \\
\hline 8 & MEMS/NEMS & $15(7)$ & 2006-2019 & 1.07 & $\begin{array}{l}\text { National Science Foundation (China), the Basic Science Research Program, through the National Research Foundation of Korea, } \\
\text { European Research Council, Ministry of Education (Malaysia), Office of Basic Energy Sciences Department of Energy (USA), } \\
\text { International Research and Development Program of the National Research Foundation of Korea }\end{array}$ \\
\hline 9 & Fluids & $8(3)$ & 2013-2020 & 1.00 & Ministry of Higher Education (Malaysia), National Natural Science Foundation (China), Australian Research Council/FCSTPty Ltd \\
\hline 10 & Ambient & $11(4)$ & 2014-2020 & 1.57 & $\begin{array}{l}\text { Center for Advanced Infrastructure and Transportation (USA), Portuguese Foundation of Science and Technology, European } \\
\text { Regional Development Fund, National Natural Science Foundation of China }\end{array}$ \\
\hline
\end{tabular}


Based on the data listed in Table 11, three lines of research were detected:

1. Pioneering topics that are still under consideration: general reviews (2005-2019), key design points (2005-2020), material-related studies (2009-2019), and MEMS-based devices (2006-2019),

2. Pioneering topics without any recent publication of review papers: modeling approaches (2008-2017), vibration-based harvesters (2004-2015), and sensors and actuators (2007-2016),

3. Newly developed topics: fluids (2013-2020), ambient waste energy (2014-2020), and biological applications (2011-2019).

\section{The Roadmap and Missing Topics}

The missing topics and the future research topics, which require further close investigation to demonstrate the state of the art, are

1. The development of hybrid multi-purpose energy generators to completely harness energy of any kind and with any characteristics, combining piezo-, pyro-, tribo-, flexo-, thermo-, and photoelectric technologies.

2. The investigation of the mathematical models and analytical and numerical solution techniques, especially in nanoscale geometries where the classical continuum mechanics principles fail, or in stochastic and non-linear situations. Some modified constitutive relations may need to be developed in non-continuum regimes. Furthermore, the second-law analysis and the analysis of such systems from the thermodynamic viewpoint are missing topics. The development ab initio first-principles simulations with an atomistic nature are other challenges for the nanoscale piezo-harvesters. The development of open-source codes such as OpenFOAM and LAMMPS to include solvers involving the piezoelectric effect may be another future research topic.

3. The application of piezo-materials in energy-saving or reducing the energy demands of a system rather than generation of energy requires a comprehensive review. An example of this energy reduction is the delay in decaying disturbances and delaying the transition to turbulence using piezo-actuators placed on the surface of bluff bodies.

4. Due to the multi-physics nature of the piezoelectric effect, it is highly recommended to prepare review papers on optimization methods or machine learning-related topics.

5. Commercialization of piezo-based harvesters and enhancing the technology readiness level require serious attention. Perhaps the next decade will be the decade of the extensive commercialization of the piezo-harvesters.

6. Plenty of patents have been published in recent years. Some review papers should even be devoted to the investigation of patents presented in the field.

7. Focused reviews are needed on vibration-based piezo-harvesters in the last four years, the development of piezotronics, and the design of completely self-powered autonomous systems.

8. The overall design of devices including all parts, integrating the whole device in thin films, accumulation in rechargeable batteries, and taking into account the energy consumption needed to store the harvested energy.

9. The optimization of device architecture and size-reducing configurations for portable applications, flexible wearable, compact, embeddable, and implantable devices.

10. In situ prototype testing and the design of harvesters coupled with environment and realistic applications to face sunlight in outdoor applications, naturally occurring stochastic vibrations, wind speed variations, dust, and noises, as well as having the required flexibility to fit the shapes of human organs, and waterproofness.

11. Quantification of the figures of merit for the piezo-material properties such as energy transforming or conversion efficiency and standardizing the performance of piezobased devices. 
12. Reducing the maintenance cost, enhancing the lifespan, ameliorating the performance, the analysis of government supports, the cost-benefit balance, and investigations of piezo-harvesting from an energy policy viewpoint.

13. Thermal design of piezo-systems, including the temperature-dependent properties and high-temperature harvesting limitations.

14. The fabrication of new piezo-materials with non-linear behavior, larger displacements, lower frequencies, wider operation bandwidth, and frequency self-adaptation capabilities.

15. The use of meta-materials, non-toxic, biocompatible, printable piezo-materials, nanofibers, lead-free and high-piezoelectric coefficient materials.

16. Improving the design of electrical circuitry and managing rectification and storage losses.

17. Modification of structural designs, including fracture-fatigue studies to increase the reliability, stability, and durability of the device.

18. The design of efficient control techniques.

19. Extending the applications of piezo-materials into novel fields such as the internet of things.

20. Paying close attention to the use of the unimorph design for a high-energy harvesting rate, obtaining realistic resonance data in order to reach compactness, investigating energy outputs much higher than $1 \mathrm{~mW}$, and step-by-step reporting of successive energy flow or efficiency from the input mechanical energy to the final electric energy in a rechargeable battery.

21. Focusing on applications involving the elimination, restriction, and replacement of toxic materials and environmental pollution.

22. The development of designs exhibiting the highest electromechanical coupling factor.

23. Considering mechanical impedance matching, electromechanical transduction, electrical impedance matching, and the priority of these factors.

24. The development of other applications as energy harvesting devices with low energy demand.

25. Designing a grid of nano-devices (thousands) or thick films (10 to 30 microns) to generate a minimum of $1 \mathrm{~mW}$ power (the required electric energy to operate a typical energy-harvesting electric circuit with a DC/DC converter).

26. General development directions may be remote signal transmission, and energy saving in rechargeable batteries.

However, the research on piezoelectric energy harvesting is not mature enough and many active interdisciplinary research fields are currently available for researchers. It should be mentioned that the progress of small-scale devices with very low power needs is tightly tied to the revolution in the design of efficient high-output-power piezoelectric energy harvesters. It is recommended to rely on fundamental principles in order to obtain unique designs for future research.

Author Contributions: Conceptualization, analysis, and methodology: all authors. All authors have read and agreed to the published version of the manuscript.

Funding: This research was supported by the Iran National Science Foundation (Grant number 98017606).

Conflicts of Interest: The authors declare no conflict of interest.

\section{References}

1. Uchino, K. Micromechatronics; CRC Press: Boca Raton, FL, USA, 2019.

2. Dutoit, N.E.; Wardle, B.L.; Kim, S.G. Design considerations for MEMS-scale piezoelectric mechanical vibration energy harvesters. Integr. Ferroelectr. 2005, 71, 121-160. [CrossRef]

3. Uchino, K. Essentials of Piezoelectric Energy Harvesting; World Scientific Publishing: Singapore, 2021.

4. Safaei, M.; Sodano, H.A.; Anton, S.R. A review of energy harvesting using piezoelectric materials: State-of-the-art a decade later (2008-2018). Smart Mater. Struct. 2019, 28, 113001. [CrossRef] 
5. Anton, S.R.; Sodano, H.A. A review of power harvesting using piezoelectric materials (2003-2006). Smart Mater. Struct. 2007, 16, R1. [CrossRef]

6. Taware, S.M.; Deshmukh, S.P. A review of energy harvesting from piezoelectric materials. IOSR J. Mech. Civ. Eng. (IOSR-JMCE) 2013, 2320-334X, 43-50.

7. Sharma, P.K.; Baredar, P.V. Analysis on piezoelectric energy harvesting small scale device: A review. J. King Saud Univ.-Sci. 2019, 31, 869-877. [CrossRef]

8. Mateu, L.; Moll, F. Review of energy harvesting techniques and applications for microelectronics. In VLSI Circuits and Systems II; International Society for Optics and Photonics: Washington, DC, USA, 2005; Volume 5837, pp. 359-373.

9. Calio, R.; Rongala, U.B.; Camboni, D.; Milazzo, M.; Stefanini, C.; De Petris, G.; Oddo, C.M. Piezoelectric energy harvesting solutions. Sensors 2014, 14, 4755-4790. [CrossRef]

10. Sun, C.H.; Shang, G.Q.; Tao, Y.Y.; Li, Z.R. A review on application of piezoelectric energy harvesting technology. In Advanced Materials Research; Trans Tech Publications Ltd.: Zurich, Switzerland, 2012; Volume 516, pp. 1481-1484.

11. Khaligh, A.; Zeng, P.; Zheng, C. Kinetic energy harvesting using piezoelectric and electromagnetic technologies-state of the art. IEEE Trans. Ind. Electron. 2009, 57, 850-860. [CrossRef]

12. Batra, A.K.; Alomari, A.; Chilvery, A.K.; Bandyopadhyay, A.; Grover, K. Piezoelectric power harvesting devices: An overview. Adv. Sci. Eng. Med. 2016, 8, 1-12. [CrossRef]

13. Sharma, S.; Sharma, N.C.; Upadhayay, A.; Hore, D. An Innovative Strategy of Energy Generation using Piezoelectric Materials: A Review. ADBU J. Eng. Technol. 2018, 7, 007010609.

14. Gosavi, S.K.; Balpande, S.S. A Comprehensive Review of Micro and Nano Scale Piezoelectric Energy Harvesters. Sens. Lett. 2019, 17, 180-195. [CrossRef]

15. Bedekar, V.; Oliver, J.; Zhang, S.; Priya, S. Comparative study of energy harvesting from high temperature piezoelectric single crystals. Jpn. J. Appl. Phys. 2009, 48, 091406. [CrossRef]

16. Li, H.; Tian, C.; Deng, Z.D. Energy harvesting from low frequency applications using piezoelectric materials. Appl. Phys. Rev. 2014, 1, 041301. [CrossRef]

17. Narita, F.; Fox, M. A review on piezoelectric, magnetostrictive, and magnetoelectric materials and device technologies for energy harvesting applications. Adv. Eng. Mater. 2018, 20, 1700743. [CrossRef]

18. Zaarour, B.; Zhu, L.; Huang, C.; Jin, X.; Alghafari, H.; Fang, J.; Lin, T. A review on piezoelectric fibers and nanowires for energy harvesting. J. Ind. Text. 2019, 51, 297-340. [CrossRef]

19. Yuan, X.; Changgeng, S.; Yan, G.; Zhenghong, Z. Application review of dielectric electroactive polymers (DEAPs) and piezoelectric materials for vibration energy harvesting. In Journal of Physics: Conference Series; IOP Publishing: Southampton, UK, 2016; Volume 744, p. 012077.

20. Mishra, S.; Unnikrishnan, L.; Nayak, S.K.; Mohanty, S. Advances in piezoelectric polymer composites for energy harvesting applications: A systematic review. Macromol. Mater. Eng. 2019, 304, 1800463. [CrossRef]

21. Liu, H.; Zhong, J.; Lee, C.; Lee, S.W.; Lin, L. A comprehensive review on piezoelectric energy harvesting technology: Materials, mechanisms, and applications. Appl. Phys. Rev. 2018, 5, 041306. [CrossRef]

22. Bowen, C.R.; Kim, H.A.; Weaver, P.M.; Dunn, S. Piezoelectric and ferroelectric materials and structures for energy harvesting applications. Energy Environ. Sci. 2014, 7, 25-44. [CrossRef]

23. Khan, F.U.; Ahmad, I. Review of energy harvesters utilizing bridge vibrations. Shock Vib. 2016, 2016, 1340402. [CrossRef]

24. Nia, E.M.; Zawawi, N.A.W.A.; Singh, B.S.M. A review of walking energy harvesting using piezoelectric materials. IOP Conf. Ser. Mater. Sci. Eng. 2017, 291, 012026. [CrossRef]

25. Lefeuvre, E.; Sebald, G.; Guyomar, D.; Lallart, M.; Richard, C. Materials, structures and power interfaces for efficient piezoelectric energy harvesting. J. Electroceram. 2009, 22, 171-179. [CrossRef]

26. Mukherjee, A.; Datta, U. Comparative study of piezoelectric materials properties for green energy harvesting from vibration. In Proceedings of the 2010 Annual IEEE India Conference (INDICON), Kolkata, India, 17-19 December 2010; pp. 1-4.

27. Maamer, B.; Boughamoura, A.; El-Bab, A.M.F.; Francis, L.A.; Tounsi, F. A review on design improvements and techniques for mechanical energy harvesting using piezoelectric and electromagnetic schemes. Energy Convers. Manag. 2019, 199, 111973. [CrossRef]

28. Uchino, K. Piezoelectric energy harvesting systems Essentials to successful developments. Energy Technol. 2018, 6, 829-848. [CrossRef]

29. Priya, S. Advances in energy harvesting using low profile piezoelectric transducers. J. Electroceram. 2007, 19, 167-184. [CrossRef]

30. Yang, Z.; Zhou, S.; Zu, J.; Inman, D. High-performance piezoelectric energy harvesters and their applications. Joule 2018, 2, 642-669. [CrossRef]

31. Yildirim, T.; Ghayesh, M.H.; Li, W.; Alici, G. A review on performance enhancement techniques for ambient vibration energy harvesters. Renew. Sustain. Energy Rev. 2017, 71, 435-449. [CrossRef]

32. Ibrahim, S.W.; Ali, W.G. A review on frequency tuning methods for piezoelectric energy harvesting systems. J. Renew. Sustain. Energy 2012, 4, 062703. [CrossRef]

33. Talib, N.H.H.A.; Salleh, H.; Youn, B.D.; Resali, M.S.M. Comprehensive Review on Effective Strategies and Key Factors for High Performance Piezoelectric Energy Harvester at Low Frequency. Int. J. Automot. Mech. Eng. 2019, 16, 7181-7210. [CrossRef] 
34. Brenes, A.; Morel, A.; Juillard, J.; Lefeuvre, E.; Badel, A. Maximum power point of piezoelectric energy harvesters: A review of optimality condition for electrical tuning. Smart Mater. Struct. 2020, 29, 033001. [CrossRef]

35. Szarka, G.D.; Stark, B.H.; Burrow, S.G. Review of power conditioning for kinetic energy harvesting systems. IEEE Trans. Power Electron. 2011, 27, 803-815. [CrossRef]

36. Dell'Anna, F.G.; Dong, T.; Li, P.; Wen, Y.; Yang, Z.; Casu, M.R.; Azadmehr, M.; Berg, Y. State-of-the-art power management circuits for piezoelectric energy harvesters. IEEE Circuits Syst. Mag. 2018, 18, 27-48. [CrossRef]

37. Guyomar, D.; Lallart, M. Recent progress in piezoelectric conversion and energy harvesting using nonlinear electronic interfaces and issues in small scale implementation. Micromachines 2011, 2, 274-294. [CrossRef]

38. Selvan, K.V.; Ali, M.S.M. Micro-scale energy harvesting devices: Review of methodological performances in the last decade. Renew. Sustain. Energy Rev. 2016, 54, 1035-1047. [CrossRef]

39. Kim, S.G.; Priya, S.; Kanno, I. Piezoelectric MEMS for energy harvesting. MRS Bull. 2012, 37, 1039-1050. [CrossRef]

40. Toprak, A.; Tigli, O. Piezoelectric energy harvesting: State-of-the-art and challenges. Appl. Phys. Rev. 2014, 1, 031104. [CrossRef]

41. Todaro, M.T.; Guido, F.; Mastronardi, V.; Desmaele, D.; Epifani, G.; Algieri, L.; De Vittorio, M. Piezoelectric MEMS vibrational energy harvesters: Advances and outlook. Microelectron. Eng. 2017, 183, 23-36. [CrossRef]

42. Briscoe, J.; Dunn, S. Piezoelectric nanogenerators: A review of nanostructured piezoelectric energy harvesters. Nano Energy 2015, 14, 15-29. [CrossRef]

43. Beeby, S.P.; Tudor, M.J.; White, N.M. Energy harvesting vibration sources for microsystems applications. Meas. Sci. Technol. 2006, 17, R175. [CrossRef]

44. Salim, M.; Aljibori, H.S.S.; Salim, D.; Khir, M.H.M.; Kherbeet, A.S. A review of vibration-based MEMS hybrid energy harvesters. J. Mech. Sci. Technol. 2015, 29, 5021-5034. [CrossRef]

45. Kumar, B.; Kim, S.W. Energy harvesting based on semiconducting piezoelectric ZnO nanostructures. Nano Energy 2012, 1, $342-355$. [CrossRef]

46. Jing, Q.; Kar-Narayan, S. Nanostructured polymer-based piezoelectric and triboelectric materials and devices for energy harvesting applications. J. Phys. D Appl. Phys. 2018, 51, 303001. [CrossRef]

47. Wang, X. Pieogenerators Harvesting ambient mechanical energy at the nanometer scale. Nano Energy 2012, 1, 13-24. [CrossRef]

48. Wang, Z.; Pan, X.; He, Y.; Hu, Y.; Gu, H.; Wang, Y. Piezoelectric nanowires in energy harvesting applications. Adv. Mater. Sci. Eng. 2015, 2015, 165631. [CrossRef]

49. Muralt, P.; Polcawich, R.G.; Trolier-McKinstry, S. Piezoelectric thin films for sensors, actuators, and energy harvesting. MRS Bull. 2009, 34, 658-664. [CrossRef]

50. Khan, A.; Abas, Z.; Kim, H.S.; Oh, I.K. Piezoelectric thin films: An integrated review of transducers and energy harvesting. Smart Mater. Struct. 2016, 25, 053002. [CrossRef]

51. Erturk, A.; Inman, D.J. On mechanical modeling of cantilevered piezoelectric vibration energy harvesters. J. Intell. Mater. Syst. Struct. 2008, 19, 1311-1325. [CrossRef]

52. Erturk, A.; Inman, D.J. Issues in mathematical modeling of piezoelectric energy harvesters. Smart Mater. Struct. 2008, 17, 065016. [CrossRef]

53. Zhao, L.; Tang, L.; Yang, Y. Comparison of modeling methods and parametric study for a piezoelectric wind energy harvester. Smart Mater. Struct. 2013, 22, 125003. [CrossRef]

54. Wei, C.; Jing, X. A comprehensive review on vibration energy harvesting: Modelling and realization. Renew. Sustain. Energy Rev. 2017, 74, 1-18. [CrossRef]

55. Abdelkefi, A. Aeroelastic energy harvesting: A review. Int. J. Eng. Sci. 2016, 100, 112-135. [CrossRef]

56. Sodano, H.A.; Inman, D.J.; Park, G. A review of power harvesting from vibration using piezoelectric materials. Shock Vib. Dig. 2004, 36, 197-206. [CrossRef]

57. Kim, H.S.; Kim, J.H.; Kim, J. A review of piezoelectric energy harvesting based on vibration. Int. J. Precis. Eng. Manuf. 2011, 12, 1129-1141. [CrossRef]

58. Siddique, A.R.M.; Mahmud, S.; Van Heyst, B. A comprehensive review on vibration based micro power generators using electromagnetic and piezoelectric transducer mechanisms. Energy Convers. Manag. 2015, 106, 728-747. [CrossRef]

59. Saadon, S.; Sidek, O. A review of vibration-based MEMS piezoelectric energy harvesters. Energy Convers. Manag. 2011, 52, 500-504. [CrossRef]

60. Harb, A. Energy harvesting: State-of-the-art. Renew. Energy 2011, 36, 2641-2654. [CrossRef]

61. Zhu, D.; Tudor, M.J.; Beeby, S.P. Strategies for increasing the operating frequency range of vibration energy harvesters: A review. Meas. Sci. Technol. 2009, 21, 022001. [CrossRef]

62. Harne, R.L.; Wang, K.W. A review of the recent research on vibration energy harvesting via bistable systems. Smart Mater. Struct. 2013, 22, 023001. [CrossRef]

63. Hwang, G.T.; Byun, M.; Jeong, C.K.; Lee, K.J. Flexible piezoelectric thin-film energy harvesters and nanosensors for biomedical applications. Adv. Healthc. Mater. 2015, 4, 646-658. [CrossRef]

64. Ali, F.; Raza, W.; Li, X.; Gul, H.; Kim, K.H. Piezoelectric energy harvesters for biomedical applications. Nano Energy 2019, 57, 879-902. [CrossRef] 
65. Surmenev, R.A.; Orlova, T.; Chernozem, R.V.; Ivanova, A.A.; Bartasyte, A.; Mathur, S.; Surmeneva, M.A. Hybrid lead-free polymer-based scaffolds with improved piezoelectric response for biomedical energy-harvesting applications: A review. Nano Energy 2019, 62, 475-506. [CrossRef]

66. Zheng, Q.; Shi, B.; Li, Z.; Wang, Z.L. Recent progress on piezoelectric and triboelectric energy harvesters in biomedical systems. Adv. Sci. 2017, 4, 1700029. [CrossRef]

67. Riemer, R.; Shapiro, A. Biomechanical energy harvesting from human motion: Theory, state of the art, design guidelines, and future directions. J. Neuroeng. Rehabil. 2011, 8, 22. [CrossRef] [PubMed]

68. Mhetre, M.R.; Nagdeo, N.S.; Abhyankar, H.K. Micro energy harvesting for biomedical applications: A review. In Proceedings of the IEEE 2011 3rd International Conference on Electronics Computer Technology, Kanyakumari, India, 8-10 April 2011; Volume 3, pp. $1-5$.

69. Xin, Y.; Li, X.; Tian, H.; Guo, C.; Qian, C.; Wang, S.; Wang, C. Shoes-equipped piezoelectric transducer for energy harvesting: A brief review. Ferroelectrics 2016, 493, 12-24. [CrossRef]

70. Wang, J.; Geng, L.; Ding, L.; Zhu, H.; Yurchenko, D. The state-of-the-art review on energy harvesting from flow-induced vibrations. Appl. Energy 2020, 267, 114902. [CrossRef]

71. Truitt, A.; Mahmoodi, S.N. A review on active wind energy harvesting designs. Int. J. Precis. Eng. Manuf. 2013, 14, 1667-1675. [CrossRef]

72. Viet, N.V.; Wu, N.; Wang, Q. A review on energy harvesting from ocean waves by piezoelectric technology. J. Model. Mech. Mater. 2017, 1. [CrossRef]

73. McCarthy, J.M.; Watkins, S.; Deivasigamani, A.; John, S.J. Fluttering energy harvesters in the wind: A review. J. Sound Vib. 2016, 361, 355-377. [CrossRef]

74. Hamlehdar, M.; Kasaeian, A.; Safaei, M.R. Energy harvesting from fluid flow using piezoelectrics: A critical review. Renew. Energy 2019, 143, 1826-1838. [CrossRef]

75. Wong, C.H.; Dahari, Z.; Manaf, A.A.; Miskam, M.A. Harvesting raindrop energy with piezoelectrics: A review. J. Electron. Mater. 2015, 44, 13-21. [CrossRef]

76. Elahi, H.; Eugeni, M.; Gaudenzi, P. A review on mechanisms for piezoelectric-based energy harvesters. Energies 2018, 11, 1850 [CrossRef]

77. Chua, K.G.; Hor, Y.F.; Lim, H.C. Raindrop kinetic energy piezoelectric harvesters and relevant interface circuits: Review, issues and outlooks. Sens. Transducers 2016, 200, 1.

78. Guo, L.; Lu, Q. Potentials of piezoelectric and thermoelectric technologies for harvesting energy from pavements. Renew. Sustain. Energy Rev. 2017, 72, 761-773. [CrossRef]

79. Duarte, F.; Ferreira, A. Energy harvesting on railway tracks: State-of-the-art. In Proceedings of the Institution of Civil EngineersTransport; Thomas Telford Ltd.: London, UK, 2017; Volume 170, pp. 123-130.

80. Wang, H.; Jasim, A.; Chen, X. Energy harvesting technologies in roadway and bridge for different applications A comprehensive review. Appl. Energy 2018, 212, 1083-1094. [CrossRef]

81. Pillai, M.A.; Deenadayalan, E. A review of acoustic energy harvesting. Int. J. Precis. Eng. Manuf. 2014, 15, 949-965. [CrossRef]

82. Khan, F.U.; Izhar State of the art in acoustic energy harvesting. J. Micromech. Microeng. 2015, 25, 023001. [CrossRef]

83. Duarte, F.; Ferreira, A. Energy harvesting on road pavements: State of the art. Proc. Inst. Civ. Eng.-Energy 2016, 169, 79-90. [CrossRef]

84. Al-Yafeai, D.; Darabseh, T.; Mourad, A.H.I. A State-Of-The-Art Review of Car Suspension-Based Piezoelectric Energy Harvesting Systems. Energies 2020, 13, 2336. [CrossRef]

85. Dagdeviren, C.; Joe, P.; Tuzman, O.L.; Park, K.I.; Lee, K.J.; Shi, Y.; Huang, Y.; Rogers, J.A. Recent progress in flexible and stretchable piezoelectric devices for mechanical energy harvesting, sensing and actuation. Extrem. Mech. Lett. 2016, 9, 269-281. [CrossRef] 